\title{
NMDA receptors control cortical axonal projections via EPHRIN-B/EPHB signaling
}

Jing Zhou ${ }^{1,2}$, Yong Lin ${ }^{1,3}$, Trung Huynh ${ }^{1,2}$, Hirofumi Noguchi ${ }^{1,2}$, Jeffrey O. Bush ${ }^{4}$, Samuel J. Pleasure ${ }^{1,2,5}$

1. Department of Neurology, University of California, San Francisco, San Francisco, CA 94143, USA.

2. Weill Institute for Neurosciences, University of California, San Francisco, San Francisco, CA 94143, USA.

3. Department of Neurological Surgery, Ren Ji Hospital, School of Medicine, Shanghai Jiao Tong University, 160 Pujian Road, Shanghai 200127, P.R. China.

4. Department of Cell and Tissue Biology, Program in Craniofacial Biology and Institute for Human Genetics, University of California San Francisco CA 94143, USA; Eli and Edythe Broad Center of Regeneration Medicine and Stem Cell Research, University of California, San Francisco, San Francisco, CA 94143.

5. Programs in Neuroscience and Developmental Stem Cell Biology, Eli and Edythe Broad Center of Regeneration Medicine and Stem Cell Research, Kavli Institute for Fundamental Neuroscience, San Francisco, CA 94143, USA.

Electronic address: samuel.pleasure@ucsf.edu

\begin{abstract}
Callosal projections from primary somatosensory cortex (S1) are key for processing somatosensory inputs and integrating sensory-motor information. How the callosal innervation pattern in S1 is formed during early postnatal development is not clear. We found that the normal termination pattern of these callosal projections is disrupted in cortex specific NMDAR mutants. Rather than projecting selectively to the primary/secondary somatosensory cortex (S1/S2) border, axons were uniformly distributed throughout $\mathrm{S} 1$. In addition, the density of this projection increased over postnatal life until the mice died by P30. By combining genetic and antibodymediated loss of function, we demonstrated that it is NR2B-containing NMDA receptors in target S1 that mediate this guidance phenotype, thus playing a central role in interhemispheric connectivity. Furthermore, we found that this function of NMDA receptors in callosal circuit formation is independent of ion channel function and instead depends on interactions with EPHRIN-B/EPHB. Thus, NMDAR cooperates with EPHRIN-B/EPHB in target S1 to control the formation callosal circuits by acting as an accessory axon guidance receptor modulating EPH-dependent repulsion.
\end{abstract}

\section{Introduction}

Synaptic connections between neurons form circuits that can convey neural information. Abnormalities at any stage of synaptic circuit development can result in neuropsychiatric pathology. The corpus callosum (CC) is the largest interhemispheric commissural circuit in mammals. The connectivity of the $\mathrm{CC}$ is essential for 
coordinated sensory-motor function and for many higher cognitive processes, and CC pathology is implicated in a variety of developmental disorders (Paul, 2011).

Callosal projections originate from pyramidal neurons located in layers II/III, V and VI and traverse the CC to form synapses with neurons in contralateral homotopic or heterotopic cortical areas. We previously showed (Zhou et al., 2013) that the medial-lateral topography of callosal neurons in the cortex is tightly constrained by the Dorsal-Ventral (D-V) position of axons within the CC. The axon position within the $\mathrm{CC}$ determines its terminal location in the contralateral cortex, with dorsally-located axons projecting medially and ventrallylocated axons projecting laterally. As such, the spatial organization of topographically represented information from one hemisphere is preserved as it is projected onto the contralateral hemisphere. However, the molecular determinants regulating proper targeting of commissural projections remain unknown.

In vivo $\mathrm{Ca}^{2+}$ imaging and multiunit recordings show distinct patterns of neural activity in the cortex of newborn mice (Adelsberger et al., 2005; Khazipov and Luhmann, 2006; Khazipov et al., 2004). These activity patterns synchronize spatially and temporally distinct neural networks and may play important roles in wiring cortical maps (Allene et al., 2008; Golshani et al., 2009; Yang et al., 2009). Suppressing endogenous neural activity by overexpressing the inward rectifying potassium channel Kir2.1 in callosal neurons delays axon growth and results ultimately in layer-targeting defects in visual cortex and somatosensory cortex (Mizuno et al., 2007; Rodriguez-Tornos et al., 2016; Wang et al., 2007). Sensory deprivation by ablating whiskers or transecting the infraorbital nerve (ION) before P5 blocks sensory activity to the trigeminal nerve and disrupts barrel field formation in primary somatosensory cortex (S1) with secondary disruption of callosal innervation at the S1/S2 border (Huang et al., 2013; Suarez et al., 2014). These studies show that directly reducing neural activity or blocking ascending sensory inputs to callosal neurons affects callosal targeting and map formation. However, the molecular mechanisms governing these events are not clear.

Neural activity is generally propagated from the axons of presynaptic neurons to the dendrites of postsynaptic neurons by the secretion of neurotransmitters. Neurotransmitter receptors located on the postsynaptic neuron regulate synaptic transmission. The NMDA receptor (NMDAR) is a glutamatergic neurotransmitter receptor located at the synapses that mediates the vast majority of excitatory neurotransmission in the cortex (Traynelis et al., 2010). NMDAR mediated synaptic transmission is important in generating synchronized activity patterns in immature cortex, suggesting that NMDAR $\mathrm{Ca}^{2+}$ channel may be involved in neural circuit formation.

In this study we examined the role of NMDAR in the formation of callosal circuitry. Initially, our hypothesis was that NMDARs would be important modulators of callosal circuit formation and that this would be mediated through the ion channel function by regulating neural activity. Indeed, we did find a crucial role for NMDAR in regulating callosal innervation patterns. To our surprise, this was not mediated by the ion channel function of NMDAR. Rather, there was a specific role for the NR2B-containing NMDAR and interactions between NMDAR and EPHRIN-B/EPHB. EPHB2 is known to be necessary for localization of NMDAR to synapses 
(Nolt et al., 2011), however, we found that this requirement was reciprocal - when NMDARs are lost, EPHB2 protein expression during development is lost as well. Most importantly, this is the first demonstration that interactions between NMDAR and EPHRIN-B/EPHB are required for neural circuit formation during development.

\section{Results}

\section{Postnatal development of the S1 callosal projection}

The development of commissural S1 projections serves as an ideal model to study interhemispheric circuit development. To understand normal development of the S1 callosal projection, we labelled the progenitor cells for layer II/III neurons with enhanced green fluorescent protein (EGFP) by in utero electroporation at embryonic day (E) 15.5 and examined callosal development at four critical time points (Figure 1). At postnatal day (P) 5, the callosal axons from S1 had reached the white matter underneath contralateral S1 (Figure 1B). At P8, the callosal axons were diffusely distributed in contralateral S1 (Figure 1C). By P12, pruning of excess projections led to a refined innervation pattern with a narrow band limited to the S1/S2 border (Figure 1D). After P12, the pattern is generally stable, as shown at P30 (Figure 1E).

\section{NR1 knock-out (KO) mice have disrupted callosal innervation}

NMDARs are heteromeric receptor channel complexes that differ in subunit composition. To date, seven different subunits have been identified: the NR1 subunit, four distinct NR2 subunits (A-D), and a pair of NR3 subunits. The NR1 subunit is the essential subunit of NMDARs (Dingledine et al., 1999; Paoletti et al., 2013). Global NR1 knockout mice die within a few hours of birth (Forrest et al., 1994). To explore the role of NMDAR in callosal development, we generated cortex-specific NR1 knock-out (KO) mice by crossing a floxed NR1 allele mice $\left(N R f^{f l f l}\right)$ with Emx1-Cre recombinase (Cre) mice $\left(E m x l^{\text {cre/+ }}\right)$ thereby selectively deleting NR1 in excitatory cortical projection neurons. Since NR1 is essential, NR1 deletion results in loss of functional NMDARs in cortical excitatory neurons. Immunostaining at P8 showed that expression of cortical NR1 was greatly diminished (Figure 1-figure supplementary 1) in NR1 KO mice. Consistent with previous studies (Iwasato et al., 2000; Lo et al., 2013), the organization of thalamocortical barrels in Layer IV of S1 was somewhat disrupted but still apparent in NR1 KO mice at P8, as revealed by vesicular glutamate transporter 2 (VGlut2) immunostaining (Figure 1-figure supplementary 1).

To investigate whether NMDAR plays a role in the targeting of callosal projections to contralateral cortex, we first examined the callosal innervation pattern at P14, by which point the mature pattern has formed. In littermate controls $\left(E m x l^{c r e /+} ; N R l^{f l / w t}\right)$, a dense area of innervation was formed at the S1/S2 border (Figure 1F) and the overall pattern was the same as wild-type controls in Figure 1D. However, in NR1 KO mice $\left(E m x l^{\text {cre } /+}\right.$; $N R I^{f l f l}$ mice), the normal restricted pattern of callosal targeting to the $\mathrm{S} 1 / \mathrm{S} 2$ border was absent, and callosal 
axons were uniformly distributed throughout the contralateral somatosensory cortex (Figure 1G). Quantitative fluorescence intensity analysis showed that the axon distribution pattern in S1 was statistically significantly different between littermate control and NR1 KO mice (Figure 1H). Additionally, fluorescence density analysis showed that NR1 KO mice also had more overall callosal axons innervating S1 at P14 (Figure 1I). This result suggests that the NMDAR plays a role in callosal circuit formation. In the absence of NMDAR, the targeted callosal innervation of the S1/S2 border was lost, and the overall callosal innervation in S1 was significantly increased. NR1 KO mice were smaller than littermate controls after P5 (data not shown) and rarely survived past P30 so we chose P30 as the last time point to determine if this defect persists. We found that this phenotype worsens after P14 (Figure 1J-1L).

\section{NR1 KO mice prematurely innervate S1}

To determine when this prominent targeting defect can first be detected, we examined different time points (P0, P3, P5 and P6) corresponding to critical phases of initial CC circuit formation - initial axon extension to ipsilateral $\mathrm{CC}(\mathrm{P} 0)$, axons crossing the midline (P3), axons reaching the white matter underneath contralateral S1 (P5) and axons starting to innervate S1 (P6). NR1 KO mice showed no differences with littermate controls at P0, P3 and P5 (Figure 2-figure supplementary 1) indicating no difference in the overall rate of axon growth. However, NR1 KO mice showed earlier and increased innervation of S1 at P6, when callosal axons start entering the contralateral cortex (Figure 2B, 2E). In control littermates, at P6, callosal axons were gathered into a bundle under contralateral S1 with few axons penetrating into S1. The penetrating axons in S1 were distributed across layer VI (“*” in S1 in Figure 2A), and layer V (arrows in S1 in Figure 2A) but failed to penetrate to more superficial layers. In contrast, axons targeting S1 in NR1 KO mice at P6 had extended past layer V, with many axons terminating in layer II/III (arrows in S1 in Figure 2B). Interestingly, while control mice showed equal degrees of callosal innervation from medial to lateral S1 (see arrows in S1 in Figure 2A), NR1 KO mice showed preferential early callosal innervation of medial S1 (see arrows in S1 in Figure 2B), and this was even more apparent at P8 (Figure 2C, 2D).

Because this defect was first detected at P6, we wondered whether increased cell death of target cortical neurons could account for the mis-innervation of S1. We used active (cleaved) caspase-3 as a marker of cell death in control and NR1 KO mice at P6. In control mice, cleaved caspase- $3^{+}$cells were mostly detected in layer II/III of primary motor cortex (M1), and rarely were observed in other cortical regions (Figure 2-figure supplementary 2A). Mutants did have increased cell death in layer II/III of M1 (Figure 2-figure supplementary 2B'); however, there was no increase in cell death in other cortical regions including S1 (Figure 2-figure supplementary 2B',). 
Taken together, these data indicate that the deletion of NMDAR in excitatory cortical neurons leads to premature and disrupted callosal innervation of contralateral S1. Furthermore, this excessive innervation persists and is not corrected by pruning of mistargeted axons at later developmental stages.

\section{The NMDAR is required in target neurons for normal callosal innervation}

In NR1 KO mice, the NMDAR is deleted from both projecting (presynaptic) as well as target (postsynaptic) neurons. To examine the role of NMDAR in presynaptic projecting callosal neurons, we electroporated vectors encoding Cre and EGFP into S1 of homozygous floxed NR1 mice at E15.5 (Figure 3A). Compared with littermate controls $\left(N R l^{i p s i S 1+/+}\right)$ (Figure 3B), presynaptic deletion of NR1 (NRI $1^{i p s i s l-/)}$ neurons had no discernible effect on callosal innervation at P14 (Figure 3C). This suggests that NMDAR is not required for projecting neurons to properly target S1. To determine whether NR1 is required in the S1 target neurons, we deleted NMDAR in contralateral target neurons by in utero electroporation. To delete NMDAR in all cortical layers of the contralateral cortex, a Cre vector was electroporated into NRI $I^{f l f l}$; Ail $4^{f l f l}$ mice in the contralateral/target $\mathrm{S} 1$ at E12.5 followed by a second electroporation of EGFP on E15.5 to label ipsilateral/projecting S1 (Figure 3E). Ai1 $4^{f l / f l}$ mice express the fluorescent protein tdTomato after Cre-mediated recombination, and therefore labeled cells where Cre-mediated excision occurred and thus NR1 should be deleted (Madisen et al., 2010). Control mice (NR $1^{w t / w t}$; Ail $4^{f l f l}$ mice) after double electroporation were analyzed at P14 (Figure 3F) and showed no defects. However, selective deletion of postsynaptic NR1 in experimental mice strikingly increased callosal S1 innervation (Figures 3G, 3H) similar to the deletion of NR1 in all excitatory cortical neurons (Figure 1G). These results suggest that NMDAR is required in the target neurons only for normal callosal circuit formation.

Since the phenotype we observed at P6 consisted of axons projecting past layers V and VI (Figure 2), we also performed double electroporation experiments removing NR1 in target neurons after Layer V and VI were born (E13.5) and found that deleting NMDAR in upper contralateral cortical layers by electroporating Cre into $N R 1^{f l f l}$; Ai1 $4^{f l f l}$ mice had no effect on callosal innervation at P14 (Figure 3-figure supplementary 1). Taken together, these data suggest that contralateral/target expression of NMDAR specifically in deeper cortical layers is required for callosal axon targeting rather than NMDAR expression in more superficial layers.

\section{Increased callosal innervation in $\mathrm{S} 1$ after contralateral injection of anti-NMDAR antibodies}

NMDAR antibodies directed to an extracellular domain of NR1 are known to downregulate the numbers of surface NMDARs. To further examine that it is the contralateral/target expression of NMDAR in deep cortical layers is required for callosal axon targeting, we decided to use infusions of anti-NR1 antibodies to block NMDAR function and expression in a temporally specific manner. We chose a commercial antibody against the amino acid residues 385-399 in the extracellular N-terminal domain of NR1. It has been shown that this 
antibody can alter the surface distribution and dynamics of NMDAR (Dupuis et al., 2014). To examine the efficiency of injection and whether the injection itself can cause brain damage, we injected the anti-NR1 antibodies into the lateral ventricle from P2 to P8 and perfused the mice 3 hours after the last injection. The distribution of anti-NR1 antibodies was most abundant in deep cortical layers of the ipsilateral injected hemisphere (Figure 4-figure supplementary 1). Thus, presumably due to the widespread high level of expression of NR1, the antibodies are not distributed widely in the cortex, but rather remain predominantly on the side of injection.

Next, we injected the anti-NR1 antibodies into the lateral ventricle from P2 to P12 either ipsilateral or contralateral to the origin of EGFP labeled callosal neurons and examined callosal innervation patterns at P14. The fluorescence density analysis at P14 showed that the contralateral (Figure 4E-4H) but not ipsilateral antibody injections (Figure 4A-4D) led to more overall callosal innervation in S1 at P14. This further supports our genetic data that contralateral/target expression of NMDAR in deep cortical layers is required for callosal axon targeting.

\section{NMDAR are required specifically during callosal axon growth into contralateral S1}

The antibody injections from P2 to P12 cover all the critical postnatal phases of CC development - a) axons crossing midline (P3); b) axons reaching the CC underneath contralateral S1 (P5); c) growth into S1 (P6-P8); and d) the refinement of projections (P8-P12). Thus, it is difficult to be certain when during this time the antibodies are acting to cause the observed increased callosal innervation. Our genetic data indicates the role of NMDAR in callosal development is first seen during the process of callosal axon growth into S1. However, the callosal innervation pattern in S1 does not only include the process of projecting into S1 but also the later refinement of projection. To address the temporal role of NMDAR in callosal development, we injected antibodies either from P4 to P8 or from P8 to P14 and examined the callosal innervation pattern at P14. We found that antibody injections from P4 to P8 had increased callosal axonal growth into S1 similar to that observed in NMDAR genetic deletion mice (Figure 5A-5D). However, antibody injections only from P8 to P14 had no effect on the overall callosal innervation pattern and we saw no increased callosal innervation in S1 (Figure 5E-5H). As mentioned before, the NR1 KO mice showed earlier and increased innervation of S1 when the callosal axons started entering target cortex at P6 (Figure 2B), but there was no difference between NR1 KO and littermate controls before P6 (Figure 2-figure supplementary 1). Thus, taking the genetic and antibody injection data together suggests that the crucial effect of NMDAR on callosal circuit formation is primarily during callosal projection into the cortex (P6-P8).

\section{NR2B, but not NR2A, is required for callosal axon targeting}


NR1 is an obligatory component of tetrameric NMDA receptors and is required for assembly of functional NMDAR. Therefore, NMDARs were entirely absent from excitatory cortical projection neurons in our NR1 KO mice. In the forebrain, NR1 primarily assembles with NR2A and NR2B to form functional NMDARs. NR2Aand NR2B-containing NMDARs are functionally distinct (Kutsuwada et al., 1992; Loftis and Janowsky, 2003) and follow different developmental expression trajectories with NR2B as the major NR2 subunit during the first postnatal week and NR2A expression present but increasing thereafter (Liu et al., 2004; Monyer et al., 1994; Sans et al., 2000; Sheng et al., 1994). We wondered whether NR2A-containing or NR2B-containing NMDARs play different roles in $\mathrm{S} 1$ callosal development. Thus, we crossed $E m x 1^{\text {cre/+ }}$ mice with $N R 2 A^{f l / f l}$ mice (NR2A KO) and $N R 2 B^{f l f l}$ mice (NR2B KO) (Gray et al., 2011).

In NR2A KO mice, the overall callosal innervation pattern was similar to control mice, although there was increased callosal innervation at the M1/S1 border (Figure 6A-6C). The body size of NR2A KO mice was not significantly different from littermate controls, and they survived to adulthood. At P30, the general callosal innervation pattern of NR2A KO mice was similar to littermate controls, however the increased callosal innervation at the M1/S1 border persisted (Figure 6-figure supplementary 1A-1C). In contrast, NR2B deletion phenocopied NR1 deletion with increased S1 innervation and loss of targeted innervation of the S1/S2 border at P14 (Figure 6D-6F). Similar to NR1 KO mice, NR2B KO mice were smaller than littermate controls after P5 and rarely survived past P30. Like NR1 KO mice, this phenotype continued to worsen after P14 (Figure 6figure supplementary 1D-1F). Either NR2A-containing or NR2B-containing NMDAR are channel competent andNR2A-containing NMDARs are present in the cortex ofNR2B KO mice, thus it seems possible that NMDAR's role in callosal circuit development may be separable from its channel activity.

\section{NMDAR regulates callosal circuit development independent of NMDAR channel activity}

$\mathrm{Ca}^{2+}$ influx through NMDARs is essential for synaptogenesis, experience-dependent synaptic remodeling and long-lasting changes in synaptic efficacy such as long-term potentiation (LTP) and long-term depression (LTD) (Collingridge et al., 2004; Lau and Zukin, 2007). However, accumulating evidence shows that there are NMDAR functions independent of its ion-influx, such as, NMDAR-dependent LTD which can be induced independent of $\mathrm{Ca}^{2+}$ influx (Dore et al., 2016). In models of ischemic stroke, neuronal death caused by overactivation of NMDAR is also independent of $\mathrm{Ca}^{2+}$ influx, but dependent on signaling complexes formed by NMDARs, Src kinase and Panx1 (Weilinger et al., 2016). To address whether channel activity of the NMDAR is required in callosal targeting, we systemically injected MK-801, a non-competitive NMDAR antagonist during CC development. MK-801 enters the open NMDAR channel and binds to the "blocking site" located deep in the pore, blocking $\mathrm{Ca}^{2+}$ influx through NMDAR (Huettner and Bean, 1988) (Figure 7A). We identified a dose of $1 \mathrm{mg} / \mathrm{kg}$ MK-801 (see STAR Methods for detail) to block $\mathrm{Ca}^{2+}$ influx of NMDAR from P4 to P12 and 
examined the callosal innervation pattern at P14 (Figure 7A-7D). Compared with saline control, MK801-treated pups gained weight slowly and developed opisthotonic posturing of limbs and head (data not shown), suggesting the channel function of NMDAR had been blocked. However, the normal callosal innervation pattern in these pups was similar to saline-treated controls (Figure 7B-7D).

We also performed similar experiments using D(-)-2-amino-5-phosphonopentanoic acid (D-APV), which competitively blocks the ligand (glutamate) binding site to NMDAR and inhibits channel opening, thereby preventing $\mathrm{Ca}^{2+}$ influx (Morris, 1989) (Figure 7E). We injected D-APV (5 $\mu \mathrm{g} / \mu 1,0.8-1 \mu \mathrm{l} /$ injection, see STAR Methods for detail) into the lateral ventricle of the contralateral S1 twice-daily from P4 to P12 and examined the callosal innervation pattern at P14 (Figure 7E-7H). Compared with saline control, D-APV-treated pups developed unilateral muscle contractions in limbs on the opposite side of the injection (data not shown), suggesting the channel function of NMDAR had been blocked. However, the callosal innervation pattern in these pups was again similar to saline controls (Figure 7F-7H). Taken together, these results indicate that NMDAR function in callosal targeting is independent of its channel activity.

\section{EPHB2 protein expression is decreased in NR1 KO mice}

Our studies to this point led us to consider whether the NMDAR may mediate callosal axon targeting via interaction with other guidance signaling systems. Previous studies have shown that NMDAR subunits bind directly to EPHB axon guidance receptors (Dalva et al., 2000). EPHB receptor tyrosine kinases and their transmembrane-ligands, the EPHRIN-B family, mediate short-distance cell-cell signaling and thus regulate many developmental processes at the interface between pattern formation and morphogenesis, including ordered neural maps (Kania and Klein, 2016; Niethamer and Bush, 2018). Further, several members of the EPH/EPHRIN family, including EPHRIN-B1 and EPHB2 are involved in earlier stages of corpus callosum midline axon crossing, strengthening their relevance in this context (Bush and Soriano, 2009; Orioli et al., 1996; Robichaux et al., 2016) EPHB2 and NMDARs colocalize at postsynaptic dendrites, and the extracellular domain of NMDAR interacts directly with EPHB2, an interaction driven by activation of EPHB2 by clustered EPHRIN-B1 expressed in presynaptic axon terminals (Dalva et al., 2000; Nolt et al., 2011; Palmer and Klein, 2003). Mice lacking EPHB2 have reduced levels of NMDARs at synapses in the hippocampus and cortex (Henkemeyer et al., 2003; Sheffler-Collins and Dalva, 2012), suggesting coordinated localization. EPHB2 also preferentially decreases $\mathrm{Ca}^{2+}$-dependent inactivation of NR2B-containing NMDARs but not NR2A-containing NMDARs at synapses of mature neurons (Nolt et al., 2011). In addition, EPHB2 signaling leads to phosphorylation of NR2B at tyrosine residue 1472 preventing clathrin-dependent endocytosis, and increasing the surface retention of NR2B-containing NMDARs (Chen and Roche, 2007; Nolt et al., 2011; Takasu et al., 
2002). Taken together, these pieces of evidence suggested to us that NMDAR may cooperate with EPHRINB/EPHB signaling during initial circuit formation.

We thus examined expression of EPHB2 in NMDAR KO mice by immunostaining. At P5, EPHB2 was found in both cortex and CC of controls (Figure 8-figure supplementary 1A). However, in NR1 KO mice, EPHB2 expression in the cortex was dramatically reduced (Figure 8-figure supplementary 1B). Western blots also confirmed that protein levels of EPHB2 were reduced in NR1 KO mice (Figure 8-figure supplementary 1C-1E) while mRNA levels of EPHB2 were unchanged (Figure 8-figure supplementary 1F). Given the known physical association between NMDAR and EPHB2, these data suggest reciprocity in this stabilizing interaction and dendritic localization.

\section{NMDAR cooperates with EPHRIN-B/EPHB in controlling axon targeting in S1}

EPHB2 and NMDARs colocalize at postsynaptic dendrites, and the extracellular domain of NMDAR interacts directly with EPHB2, an interaction driven by activation of EPHB2 by clustered EPHRIN-B1 expressed in presynaptic axon terminals (Dalva et al., 2000). This is consistent with the possibility that EPHRIN-B1, expressed by the projecting neuronal axons, signals through EPHB2 and NMDAR, located on the target neurons, to regulate axon extension in the contralateral cortex (Figure 8A). To test this prospect, we deleted EPHRIN-B1 in projecting neurons by electroporating vectors of Cre and EGFP at E15.5 in EphrinB $1^{f l / f l}$ mice and examined the initial callosal targeting at P6 (Figure 8B, 8C). In projecting neurons lacking EPHRINB1, callosal axons extended into the cortex past layer V, and many axons terminated in layer II/III (arrows in Figure 8C), similar to that observed in NR1 KO mice at P6 (Figure 2B).

Since this manipulation doesn't take into account potential compensation by other EPHRIN-B ligands, we blocked all EPHB2 signaling in the contralateral cortex by intraventricular injection of soluble EPHRIN-B1-Fc, from P3 to P6 and examined the initial callosal targeting at P6 (Figure 8F, 8G). EPHRINs have to be clustered in a cell membrane or artificially with, for example, antibodies to efficiently activate EPH receptors (Davis et al., 1994). Unclustered soluble EPHRINs bind EPH receptors but act as antagonists (Vearing and Lackmann, 2005). Compared with littermate controls, contralateral injection of soluble EPHRIN-B1-Fc, led to increased callosal innervation at P6 with axons penetrating to superficial layers (Figure 8F, 8G, 8J). These results support the idea EPHRIN-B1-EPHB2 play important roles in controlling callosal axon penetration into the contralateral S1 cortex.

To further determine whether there is collaboration between NMDAR and EPH-B signaling, we developed a way to assess blockade of both systems and determine if this blockade was additive, synergistic or likely acting in the same pathway. We blocked NMDAR in contralateral/target cortex by intraventricular injection of antiNR1 antibodies, from P3 to P6, and examined the initial callosal targeting at P6 (Figure 8D, 8E). Compared 
with controls, contralateral injection of anti-NR1 antibodies, caused increased callosal innervation at P6 and penetration to superficial layers of cortex (Figure 8D, 8E, 8J). Critically, blocking NMDAR and EPHRIN-B1EPHB2 signaling simultaneously in contralateral cortex by injecting both anti-NR1 antibody and EPHRIN-B1Fc did not show any additive or synergistic effects (Figure 8H-8J). This suggests that in fact NMDAR and EPHRIN-B1-EPHB2 are in the same pathway in regulating callosal targeting in S1 and is consistent with our other findings.

\section{Discussion}

In this study, we found that NMDARs cooperate with EPHRIN-B/EPHB in controlling callosal circuit formation and demonstrated that it is NR2B-containing NMDARs in target S1 cortex that regulate callosal axon targeting in S1. In mutants where either NR2B or NR1 are disrupted, there is excess axonal growth throughout $\mathrm{S} 1$. Either genetic or antibody-mediated loss of NMDAR specifically in the target hemisphere disrupted this projection. We found that this begins at P6 when axons that should terminate in deep cortical layers of target S1 instead project more superficially. Once this targeting defect begins, it continues to worsen. We believe this phenotype is most consistent with a loss of a repellant activity that normally restricts commissural axonal projections to the $\mathrm{S} 1$ cortex at initial stages of this process. Once these axons aberrantly penetrate through the deeper cortical layers of S1 in the NR1 mutants, this phenotype continues to worsen. A systematic role for NMDAR in this process was a surprise and has significant implications for disorders where NMDAR function is lost due to mutations or due to antibody-mediated disruption of NMDAR surface distribution. We predict this would be a potent disruptor of circuit formation during development certainly in this callosal circuit, but likely others as well.

\section{Mechanisms for the formation of homotopic callosal projection druing development}

Previous studies (Zhou et al., 2013), we showed that the medial-lateral topography of callosal neurons is tightly constrained by the Dorsal-Ventral (D-V) position of their axons within the CC. The axon position within the $\mathrm{CC}$ determines the contralateral cortical projection, with more dorsally-located axons projecting medially and ventrally-located axons projecting laterally. The complementary expression of chemotropic guidance cue Semaphorin3A (Sem3A) and its receptor Neuropilin-1 (Nrp1) contributes to this axonal order within the CC. The studies of genetic manipulations showed that Sema3A/Nrp1 signaling contributes to the topographic order of axons within the $\mathrm{CC}$ but is not involved in the axon position-dependent projection to the contralateral target cortex. Here, in this study, we demonstrated that contralateral/target expression of NMDAR in deep cortical layers controls the pattern of callosal projections to contralateral target S1. Interestingly, despite the disruption 
of targeting within S1 in mice with disrupted NMDAR, there is little evidence of ectopic projection to other cortical areas. This indicates that there are still other cues that regulate the generic projection to S1 but that the mechanisms we have uncovered help govern the distribution of these axons within S1.

\section{NMDARs cooperate with EPHRIN-B/EPHB signaling in deep cortical layers to regulate axon extension into the cortex}

Given the longstanding understanding of important roles for neural activity in the wiring of circuits and the generation of cortical maps, we expected that the function of NMDAR in this process would be due to the critical role of NMDAR in excitatory activity in the developing brain as synapses form. However, our data show that NMDAR ion channel function is not necessary for its role in somatosensory callosal targeting. These data are consistent with the idea that NMDAR protein complexes containing NR1 and NR2B are critical for commissural projection. This realization led us to consider whether there might be a role for NMDAR complexes in collaborating with already known axon guidance mechanisms.

Our findings suggest that without NMDAR containing NR1 and NR2B in the target cortex, there is an earlier and increased callosal innervation in S1 starting at P6, when callosal axons start entering the contralateral cortex. We believe that this observation indicates that either loss of NMDAR leads to an increase in the attractiveness of $\mathrm{S} 1$ cortex or that loss of NMDAR leads to loss of a repellant activity in the cortex that normally limits axon growth into superficial layers of S1, until axons reach the S1/S2 border. Further studies will examine whether this phenotype is due to forward EPHB or reverse EPHRIN-B signaling or both.

EPHRIN-B/EPHB signals are well known repulsive axon guidance cues. NMDARs interact with EPHB2, and the interaction is driven by the stimulation of EPHB2 by clustered EPHRIN-B1 expressed in presynaptic axon terminals, indicating that the interaction may regulate axon guidance. In addition, in anti-NMDAR encephalitis patients whose clinical syndrome is associated with antibodies against NMDAR, the anti-NMDAR antibodies not only decrease the numbers of NMDARs on the cell surface, but also disrupt the surface interaction of EPHB2 and NMDAR (Dalmau et al., 2011; Hughes et al., 2010; Jones et al., 2019; Mikasova et al., 2012). Interestingly, a previous study showed that administration of EPHRIN-B2 prevents the pathogenic effects of anti-NMDAR antibodies on levels of cell-surface NMDAR as well as the memory and behavior defects in adult mice infused with patients' CSF (Planaguma et al., 2016).

Because it is known that EPHB2 is necessary for localization of NMDAR to postsynaptic terminals, we wondered if this requirement was reciprocal and found indeed that it is - when NMDARs are lost, EPHB2 protein expression in development is lost as well. When we deleted EPHRIN-B1 only in projecting callosal axons, this also led to excess ingrowth into the $\mathrm{S} 1$ cortex visible P6-8. That this phenotype is less severe than the NMDAR phenotype is most likely due to redundancy with other EPHRIN-B ligands also expressed in projecting 
axons. To globally disrupt EPHB-EPHRIN-B interactions we injected EPHRIN-B1-Fc fragments and found that these also disrupted the somatosensory callosal targeting as efficiently as anti-NMDAR antibodies; furthermore, these two treatments were neither additive nor synergistic, implying they act through a common pathway.

Our data indicate that NMDAR are required components of EPHRIN-B/EPHB signaling in deep cortical layers that acts as a repellant to limit early growth of callosal axons into S1 cortex (Figure 9). These phenotypes are seen first at P6 when axons inappropriately enter superficial cortex in S1 so that by P30 (when the animals die) there is a nearly 6-fold increase in axonal extension into S1. This is consistent with a role for NMDAR in controlling initial projection into S1 but probably also later regulating refinement of these inappropriate projections by pruning - both core functions of axonal repellants.

\section{Materials and Methods}

\section{Experimental model and subject details}

All animal protocols were in accordance with the regulations of the National Institute of Health and approved by the University of California San Francisco Institutional Animal Care and Use Committee (IACUC). Floxed NR1 allele (Stock \#005246), EMX1-Cre (Stock \#005628) and Ai14 Cre reporter allele (Stock \# 007914) were obtained from Jackson Laboratories (Bar Harbor, ME, USA). Floxed $N R 2 A$ and $N R 2 B$ alleles were provided by the laboratory of Prof. Roger Nicoll. Floxed EphrinB1 allele was provided by the laboratory of Prof. Jeffrey Bush. Wild-type CD1 mice were obtained from Charles River Laboratories. Male and female embryos at embryonic (E) 12.5 and E15.5 were used for the in utero electroporation, and pups between postnatal day 0 (P0) to 30 (P30) for the experiments.

In utero Electroporation: DNA solution including the plasmid and $0.04 \%$ fast green was injected into the medial region of the lateral ventricle of the embryonic brain with a glass micropipette. Electrical pulses then were delivered to embryos by electrodes connected to a square-pulse generator (ECM830, BTX). For each electroporation, five $35-\mathrm{V}$ pulses of $50 \mathrm{~ms}$ were applied at $1 \mathrm{~s}$ intervals. After the electroporation, the uterus was returned to the abdominal cavity, followed by suturing of the abdominal wall and skin. Mice were perfused at different postnatal stages using 4\% paraformaldehyde followed by post-fixed overnight and incubation in 30\% sucrose at $4^{\circ} \mathrm{C} .35 \mu \mathrm{m}$-thick coronal sections were obtained using cryostat sectioning.

Plasmid: Plasmid of pCAGGS-Cre and pCAGGS-CreERT was obtained from Addgene. The ubiquitin-EGFP plasmid used was from a previous study (Zhou et al., 2013).

Antibodies: Antibodies for intraventricular injection: commercial anti-NMDAR antibody is against amino acid residues 385-399 in the N-terminus of NR1 and was made in Rabbit (AGC-001, Alomone labs). Rabbit IgG (\#31235, Invitrogen) served as control. Recombinant Mouse EPHRIN-B1 Fc Chimera Protein was obtained 
from R\&D (473-EB). Recombinant Human IgG1 Fc Protein (110-HG, R\&D) served as control. Antibodies for immunostaining: Rabbit anti-NR1 (1:500, AGC-001, Alomone labs), anti-vGlut2 (1:200, AB2251, Millipore), goat anti-EphB2 (1:50, AF467, R\&D), anti-cleaved caspase-3 (\#9661S, Cell Signaling), anti-Rabbit 594 (\#711585-152, Jackson ImmunoResearch), and anti-guinea pig 488 (A-11073, Invitrogen). Antibodies for western blot: rabbit anti-NR1 (AB9864, Millipore), goat anti-EPHB2 (1:1000, AF467, R\&D), rabbit anti-GAPDH (1:5000, \#2118, Cell Signaling) rabbit anti- $\beta$ tubulin (1:5000, \#2128, Cell Signaling), IRDye 680RD Donkey anti-Goat IgG(H+L) Ab (1:10000, \#926-68074, Li-Cor), IRDye 800CW Goat x Rabbit IgG(H+L) Ab (1:20000, \#925-32211, Li-Cor).

Intraventricular injection: Antibodies/Fc-fragment was injected to lateral ventricular of pups by glass pipette with a sharp bevel at 45 degree (BV-10 Micropipette Beveler, Sutter instrument). The diameter of pipette tip was $\sim 40-80 \mu \mathrm{m}$ (Vogt et al., 2015). The concentrations for antibody injections were $3.2 \mu \mathrm{g} / \mu \mathrm{l}$ for the commercial anti-NR1 antibody and Rabbit IgG. The concentrations for Fc injections were $2 \mu \mathrm{g} / \mu \mathrm{l}$ for EPHRIN-B1 Fc and Human IgG1 Fc. Antibodies/Fc-fragment was injected twice-daily and the injection volume was $0.8-1 \mu 1$ for each injection.

MK-801 systemic injection: EGFP positive pups were given intraperitoneal (i.p.) injection of MK-801 (1mg/kg, M107-25MG, Sigma) or equivalent volume of $0.9 \%$ saline once-daily. See the following for the criteria of selecting effective dose of MK-801. Based on literature, the single dose of MK-801 for acute i.p. administration is up to $1-10 \mathrm{mg} / \mathrm{kg}$ (Foster et al., 1988); the daily dose of MK-801 for chronic i.p. administration is around 0.30.6mg/kg (Nilsson et al., 1997; Uttl et al., 2018; Zuo et al., 2006). To optimize the dose for chronic administration, MK-801 was given to three groups pups (each group had four pups with mixed genders) from P4 to P9 with the doses of $1 \mathrm{mg} / \mathrm{kg}, 10 \mathrm{mg} / \mathrm{kg}$ and $20 \mathrm{mg} / \mathrm{kg}$, respectively. Saline was given to four pups of the same litter as control. We measured body weights of all pups every day before i.p. administration. The pups in saline group always had abundant milk in their stomachs and gained weight rapidly. The pups with the dose of $1 \mathrm{mg} / \mathrm{kg}$ had milk in their stomachs and gained weight, but very slowly. Some even lost weights. All MK-801-treated pups developed abnormal behavior-opisthotonic posturing for heads and four limbs, similar to the abnormal postures in children with anti-NMDAR encephalitis (Florance et al., 2009). The doses of $10 \mathrm{mg} / \mathrm{kg}$ and $20 \mathrm{mg} / \mathrm{kg}$ were too close to lethal dose and the pups lost weight and died within 2-3days. Thus, we chose $1 \mathrm{mg} / \mathrm{kg}$ for our experiment. The weight loss and abnormal behavior had been reported in neonatal mice after MK-801 administration (Facchinetti et al., 1993; Griesbach and Amsel, 1998; Wu et al., 2005).

D(-)-2-amino-5-phosphonopentanoic acid (D-APV) intraventricular injection: Because D-APV poorly penetrates the brain blood barrier (BBB) when administered systemically, we injected it directly into the lateral ventricle of targeted cortex. EGFP positive pups were given D-APV (5 $\mu \mathrm{g} / \mu \mathrm{l}$, Millipore-sigma, 165304-5MG) twice-daily at an injection volume of $0.8-1 \mu 1 /$ injection. See Intraventricular injection for injection detail. See 
the following for the criteria of selecting effective dose of D-APV. Based on literature, one-time infusion of $5 \mu \mathrm{g}$ D-APV into the basolateral amygdala of adult rat $(\sim 250 \mathrm{~g})$ caused memory deficit persistent for at least four weeks (Milton et al., 2008). Blocking NMDARs by intracerebral infusion of $0.5 \mu 1$ of $500 \mu \mathrm{M}$ D-APV into P7 mouse pup, reduced somatic calcium transients in pyramidal cells evoked by lateral olfactory tract stimulation, and caused memory deficits both in short-term (3hr) and long-term (24hr) odor preference memory (Mukherjee and Yuan, 2016). $0.5 \mu \mathrm{l}$ of $500 \mu \mathrm{M}$ D-APV is equal to $0.05 \mu \mathrm{g}$ D-APV (Molecular weight of D-APV: 197.13). To optimize the dose for chronic administration, intraventricular D-APV injection was given to two groups of pups (each group had four pups with mixed genders) from P4 $(\sim 4 \mathrm{~g})$ to P9 $(\sim 8 \mathrm{~g})$ with the concentrations of $5 \mu \mathrm{g} / \mu \mathrm{l}$ and10 $\mu \mathrm{g} / \mu \mathrm{l}$ twice-daily $(0.8-1 \mu \mathrm{l} /$ injection), respectively. Saline was given to four pups of the same litter as control. The body weight of all pups was measured before intraventricular injection. There were no body weight differences between Saline-treated and D-APV-treated mice. However, D-APV-treated pups in both $5 \mu \mathrm{g} / \mu \mathrm{l}-$ treated and $10 \mu \mathrm{g} / \mu \mathrm{l}$-treated groups developed unilateral muscle contractions in limbs on the opposite side of the injection within $10 \mathrm{~min}$ after injection, similar to the abnormal movements seen in MK-801-treated mice but only restricting in one side of body. No pups died during the 6 days of injections. As $5 \mu \mathrm{g} / \mu \mathrm{l}$-treated and $10 \mu \mathrm{g} / \mu \mathrm{l}$-treated had no dose-dependent effect on the abnormal behavior and based on dosage of D-APV used in literature, we chose $5 \mu \mathrm{g} / \mu \mathrm{l}$ D-APV treatment for our experiment.

Slice preparation and imaging: Mice were perfused with saline followed by $4 \%$ paraformaldehyde in phosphate buffered saline (PBS), pH7.4. Brains were removed from mice and post-fixed in $4 \%$ paraformaldehyde overnight before being placed in $30 \%$ sucrose solution. The brains were then cut into $35-\mu \mathrm{m}$ sections with cryostat (Leica VT1200S). Sections were imaged by Zeiss Axioscan Z.1 (Zeiss, Thornwood, NY, USA) with a $20 \mathrm{X}$ objective.

Immunostaining: Mouse pups were perfused with saline followed by $4 \%$ paraformaldehyde in phosphate buffered saline (PBS), pH7.4. Brains were removed from mice and post-fixed in 4\% paraformaldehyde overnight before being placed in $30 \%$ sucrose solution. The brains were then cut into $12-\mu \mathrm{m}$ sections with cryostat (Leica VT1200S). Non-specific binding was blocked by adding 5\% normal goat/donkey serum during pre-incubation and incubations in $1 \mathrm{x}$ PBS containing $0.05 \%$ TritonX-100. The primary antibodies were applied overnight at 4 degree. Secondary antibodies were applied for 1-2 hours at 4 degree and nuclei were stained with DAPI. Slides were mounted with Prolong Gold Anti-fade Mountant (P36930, Invitrogen).

Western blotting: Mouse brain tissue of somatosensory cortex from $E m x 1^{\text {cre/+}} ; N R l^{\mathrm{fl} / \mathrm{fl}}$ mice or littermate controls at P8 were collected for western blotting. Five mouse samples for each group. The protocol we used as described before (Yabut et al., 2015). 
Primers for RT-PCR: Primers for EphB2: Forward Primer-ATTATTTGCCCCAAAGTGGACTC; Reverse Primer-GCAGCGGGGTATTCTCCTTC.

RT-PCR: Mouse brain tissue of somatosensory cortex from $E m x 1^{\text {cre/+ }} ; N R 1^{\mathrm{fl} / \mathrm{fl}}$ mice or littermate controls at P8 were collected for RT-PCR. Six mouse samples for each group. The protocol we used as described before (Yabut et al., 2015).

\section{Quantification and statistical analysis}

Callosal axon distribution analysis: Using the segmented line tool in ImageJ, a line was drawn with width of 200 pixels from medial S1 to lateral S1/S2 border along cortical layer II/III. Fluorescence distribution was measured along the line by using "Plot Profile" under "Analyze" in ImageJ and produced data sets with distance points along the line $(\mathrm{X})$ and fluorescence intensity $(\mathrm{Y})$. The data was exported to Excel. In Excel, fluorescence intensity values (Y) were normalized by dividing by the max $\mathrm{Y}$ fluorescence value for that group. Finally, results were analyzed by using XY statistics in Prism version 5.0 (GraphPad Software).

Callosal axon density analysis: Sections were imaged using a Zeiss Axioscan Z.1 (Zeiss, Thornwood, NY, USA) with $20 \mathrm{X}$ objective over whole brain section. Each image was made up by the compression of three slices in $4 \mu \mathrm{m}$ Z-stack. For each brain, only one section was chosen for data quantification. The callosal axon density (fluorescence density) in S1 was quantitatively analyzed by ImageJ software. First, each picture was converted to an 8-bit image and then Brightness/Contrast (Figure 10A) and Threshold Ranges (Figure 10B) were set. Threshold Range was set to eliminate background fluorescence from affecting fluorescent density. Second, the cortical S1 region in the target side was identified according to Dapi staining as previous described (Zhou et al., 2013) and a box was drawn to encompass only the S1 (box I in Figure 10B). Third, fluorescence density was quantified in the S1 by counting the number of pixels within the threshold range and dividing by total number of pixels in the area. This is done by selecting "Area Fraction" and "Limit to Threshold" in ImageJ $\rightarrow$ Analyze $\rightarrow$ Set Measurement. Finally, the axon density in S1 was normalized by the average fluorescence density of midline for each image (box II in Figure 10B). The average fluorescence density of midline was calculated by measuring the fluorescence density of six non-overlapping points around the midline and averaging the values. A fixed sized box was used for all measurements of midline fluorescence density. Since a fixed sized box was used (total number of pixels is fixed for all), "Area" instead of "Area Fraction" was use for analysis. Results were analyzed by using two tailed T-test in Prism version 5.0 (GraphPad Software). Please note that control groups and experimental groups followed exactly the same setting of measurements.

\section{Acknowledgments}


We thank Prof. Roger Nicoll and Jillian Iafrati for providing $N R 2 A^{f l f l}$ and $N R 2 B^{f l f l}$ mice. We thank Wucheng Tao in Prof. Roger Nicoll's lab for suggestions on the experimental design of MK-801 in vivo injection. We thank Drs. Ariele L. Greenfield, Christopher M. Bartley and Michael R. Wilson for critical comments and editing for this manuscript. Work in the Pleasure lab is supported by R56 MH119435, R01MH122471, UCSF Weill Institute for Neurosciences Innovation Award, UCSF Marcus Program in Precision Medicine Innovation Transformative Integrated Research Initiative. J.O.B. is supported by R01DE023337 from NIH/NIDCR.

\section{Author contributions}

J.Z., J.O.B and S.J.P designed the experiments. J.Z., Y.L. and T.H. performed experiments. J.Z. and Y.L. analyzed the data. J.Z. and S.J.P wrote the original draft. H. $\mathrm{N}$ assisted in making diagram.

\section{Declaration of interests}

The authors declare no competing interests.

\section{References}

Adelsberger, H., Garaschuk, O., and Konnerth, A. (2005). Cortical calcium waves in resting newborn mice. Nature neuroscience 8, 988-990.

Allene, C., Cattani, A., Ackman, J.B., Bonifazi, P., Aniksztejn, L., Ben-Ari, Y., and Cossart, R. (2008). Sequential generation of two distinct synapse-driven network patterns in developing neocortex. The Journal of neuroscience : the official journal of the Society for Neuroscience 28 , 12851-12863.

Bush, J.O., and Soriano, P. (2009). Ephrin-B1 regulates axon guidance by reverse signaling through a PDZ-dependent mechanism. Genes \& development 23, 1586-1599.

Chen, B.S., and Roche, K.W. (2007). Regulation of NMDA receptors by phosphorylation. Neuropharmacology 53, 362-368.

Collingridge, G.L., Isaac, J.T., and Wang, Y.T. (2004). Receptor trafficking and synaptic plasticity. Nature reviews Neuroscience 5, 952-962.

Dalmau, J., Lancaster, E., Martinez-Hernandez, E., Rosenfeld, M.R., and Balice-Gordon, R. (2011). Clinical experience and laboratory investigations in patients with anti-NMDAR encephalitis. The Lancet Neurology 10, 63-74.

Dalva, M.B., Takasu, M.A., Lin, M.Z., Shamah, S.M., Hu, L., Gale, N.W., and Greenberg, M.E. (2000). EphB receptors interact with NMDA receptors and regulate excitatory synapse formation. Cell 103, 945-956.

Davis, S., Gale, N.W., Aldrich, T.H., Maisonpierre, P.C., Lhotak, V., Pawson, T., Goldfarb, M., and Yancopoulos, G.D. (1994). Ligands for EPH-related receptor tyrosine kinases that require membrane attachment or clustering for activity. Science 266, 816-819.

Dingledine, R., Borges, K., Bowie, D., and Traynelis, S.F. (1999). The glutamate receptor ion channels. Pharmacological reviews 51, 7-61.

Dore, K., Aow, J., and Malinow, R. (2016). The Emergence of NMDA Receptor Metabotropic Function: Insights from Imaging. Frontiers in synaptic neuroscience 8, 20. 
Dupuis, J.P., Ladepeche, L., Seth, H., Bard, L., Varela, J., Mikasova, L., Bouchet, D., Rogemond, V., Honnorat, J., Hanse, E., et al. (2014). Surface dynamics of GluN2B-NMDA receptors controls plasticity of maturing glutamate synapses. The EMBO journal 33, 842-861.

Facchinetti, F., Ciani, E., Dall'Olio, R., Virgili, M., Contestabile, A., and Fonnum, F. (1993). Structural, neurochemical and behavioural consequences of neonatal blockade of NMDA receptor through chronic treatment with CGP 39551 or MK-801. Brain research Developmental brain research $74,219-224$.

Florance, N.R., Davis, R.L., Lam, C., Szperka, C., Zhou, L., Ahmad, S., Campen, C.J., Moss, H., Peter, N., Gleichman, A.J., et al. (2009). Anti-N-methyl-D-aspartate receptor (NMDAR) encephalitis in children and adolescents. Annals of neurology 66, 11-18.

Forrest, D., Yuzaki, M., Soares, H.D., Ng, L., Luk, D.C., Sheng, M., Stewart, C.L., Morgan, J.I., Connor, J.A., and Curran, T. (1994). Targeted disruption of NMDA receptor 1 gene abolishes NMDA response and results in neonatal death. Neuron 13, 325-338.

Foster, A.C., Gill, R., and Woodruff, G.N. (1988). Neuroprotective effects of MK-801 in vivo: selectivity and evidence for delayed degeneration mediated by NMDA receptor activation. The Journal of neuroscience : the official journal of the Society for Neuroscience 8, 4745-4754.

Golshani, P., Goncalves, J.T., Khoshkhoo, S., Mostany, R., Smirnakis, S., and Portera-Cailliau, C. (2009). Internally mediated developmental desynchronization of neocortical network activity. The Journal of neuroscience : the official journal of the Society for Neuroscience 29, 10890-10899.

Gray, J.A., Shi, Y., Usui, H., During, M.J., Sakimura, K., and Nicoll, R.A. (2011). Distinct modes of AMPA receptor suppression at developing synapses by GluN2A and GluN2B: single-cell NMDA receptor subunit deletion in vivo. Neuron $71,1085-1101$.

Griesbach, G.S., and Amsel, A. (1998). Immediate and long-term effects of neonatal MK-801 treatment on nonspatial learning. Proceedings of the National Academy of Sciences of the United States of America 95, 11435-11439.

Henkemeyer, M., Itkis, O.S., Ngo, M., Hickmott, P.W., and Ethell, I.M. (2003). Multiple EphB receptor tyrosine kinases shape dendritic spines in the hippocampus. The Journal of cell biology $163,1313-1326$.

Huang, Y., Song, N.N., Lan, W., Zhang, Q., Zhang, L., Zhang, L., Hu, L., Chen, J.Y., Zhao, C.J., Li, L., et al. (2013). Sensory input is required for callosal axon targeting in the somatosensory cortex. Molecular brain 6, 53.

Huettner, J.E., and Bean, B.P. (1988). Block of N-methyl-D-aspartate-activated current by the anticonvulsant MK-801: selective binding to open channels. Proceedings of the National Academy of Sciences of the United States of America 85, 1307-1311.

Hughes, E.G., Peng, X., Gleichman, A.J., Lai, M., Zhou, L., Tsou, R., Parsons, T.D., Lynch, D.R., Dalmau, J., and Balice-Gordon, R.J. (2010). Cellular and synaptic mechanisms of anti-NMDA receptor encephalitis. The Journal of neuroscience : the official journal of the Society for Neuroscience 30, 5866-5875.

Iwasato, T., Datwani, A., Wolf, A.M., Nishiyama, H., Taguchi, Y., Tonegawa, S., Knopfel, T., Erzurumlu, R.S., and Itohara, S. (2000). Cortex-restricted disruption of NMDAR1 impairs neuronal patterns in the barrel cortex. Nature 406, 726-731.

Jones, B.E., Tovar, K.R., Goehring, A., Jalali-Yazdi, F., Okada, N.J., Gouaux, E., and Westbrook, G.L. (2019). Autoimmune receptor encephalitis in mice induced by active immunization with conformationally stabilized holoreceptors. Science translational medicine 11 .

Kania, A., and Klein, R. (2016). Mechanisms of ephrin-Eph signalling in development, physiology and disease. Nature reviews Molecular cell biology 17, 240-256.

Khazipov, R., and Luhmann, H.J. (2006). Early patterns of electrical activity in the developing cerebral cortex of humans and rodents. Trends in neurosciences 29, 414-418.

Khazipov, R., Sirota, A., Leinekugel, X., Holmes, G.L., Ben-Ari, Y., and Buzsaki, G. (2004). Early motor activity drives spindle bursts in the developing somatosensory cortex. Nature 432, 758-761. 
Kutsuwada, T., Kashiwabuchi, N., Mori, H., Sakimura, K., Kushiya, E., Araki, K., Meguro, H., Masaki, H., Kumanishi, T., Arakawa, M., et al. (1992). Molecular diversity of the NMDA receptor channel. Nature 358, 36-41.

Lau, C.G., and Zukin, R.S. (2007). NMDA receptor trafficking in synaptic plasticity and neuropsychiatric disorders. Nature reviews Neuroscience 8, 413-426.

Liu, X.B., Murray, K.D., and Jones, E.G. (2004). Switching of NMDA receptor 2A and 2B subunits at thalamic and cortical synapses during early postnatal development. The Journal of neuroscience : the official journal of the Society for Neuroscience 24, 8885-8895.

Lo, F.S., Akkentli, F., Tsytsarev, V., and Erzurumlu, R.S. (2013). Functional significance of cortical NMDA receptors in somatosensory information processing. Journal of neurophysiology 110, 26272636.

Loftis, J.M., and Janowsky, A. (2003). The N-methyl-D-aspartate receptor subunit NR2B: localization, functional properties, regulation, and clinical implications. Pharmacology \& therapeutics 97, 55-85.

Madisen, L., Zwingman, T.A., Sunkin, S.M., Oh, S.W., Zariwala, H.A., Gu, H., Ng, L.L., Palmiter, R.D., Hawrylycz, M.J., Jones, A.R., et al. (2010). A robust and high-throughput Cre reporting and characterization system for the whole mouse brain. Nature neuroscience 13, 133-140.

Mikasova, L., De Rossi, P., Bouchet, D., Georges, F., Rogemond, V., Didelot, A., Meissirel, C., Honnorat, J., and Groc, L. (2012). Disrupted surface cross-talk between NMDA and Ephrin-B2 receptors in anti-NMDA encephalitis. Brain : a journal of neurology 135, 1606-1621.

Milton, A.L., Lee, J.L., Butler, V.J., Gardner, R., and Everitt, B.J. (2008). Intra-amygdala and systemic antagonism of NMDA receptors prevents the reconsolidation of drug-associated memory and impairs subsequently both novel and previously acquired drug-seeking behaviors. The Journal of neuroscience : the official journal of the Society for Neuroscience 28, 8230-8237.

Mizuno, H., Hirano, T., and Tagawa, Y. (2007). Evidence for activity-dependent cortical wiring: formation of interhemispheric connections in neonatal mouse visual cortex requires projection neuron activity. The Journal of neuroscience : the official journal of the Society for Neuroscience 27, 6760-6770.

Monyer, H., Burnashev, N., Laurie, D.J., Sakmann, B., and Seeburg, P.H. (1994). Developmental and regional expression in the rat brain and functional properties of four NMDA receptors. Neuron $12,529-540$.

Morris, R.G. (1989). Synaptic plasticity and learning: selective impairment of learning rats and blockade of long-term potentiation in vivo by the $\mathrm{N}$-methyl-D-aspartate receptor antagonist AP5. The Journal of neuroscience : the official journal of the Society for Neuroscience 9, 3040-3057.

Mukherjee, B., and Yuan, Q. (2016). NMDA receptors in mouse anterior piriform cortex initialize early odor preference learning and L-type calcium channels engage for long-term memory. Scientific reports $6,35256$.

Niethamer, T.K., and Bush, J.O. (2018). Getting direction(s): The Eph/ephrin signaling system in cell positioning. Developmental biology.

Nilsson, M., Carlsson, A., and Carlsson, M.L. (1997). Glycine and D-serine decrease MK-801induced hyperactivity in mice. Journal of neural transmission 104, 1195-1205.

Nolt, M.J., Lin, Y., Hruska, M., Murphy, J., Sheffler-Colins, S.I., Kayser, M.S., Passer, J., Bennett, M.V., Zukin, R.S., and Dalva, M.B. (2011). EphB controls NMDA receptor function and synaptic targeting in a subunit-specific manner. The Journal of neuroscience : the official journal of the Society for Neuroscience 31, 5353-5364.

Orioli, D., Henkemeyer, M., Lemke, G., Klein, R., and Pawson, T. (1996). Sek4 and Nuk receptors cooperate in guidance of commissural axons and in palate formation. The EMBO journal 15, 60356049.

Palmer, A., and Klein, R. (2003). Multiple roles of ephrins in morphogenesis, neuronal networking, and brain function. Genes \& development 17, 1429-1450. 
Paoletti, P., Bellone, C., and Zhou, Q. (2013). NMDA receptor subunit diversity: impact on receptor properties, synaptic plasticity and disease. Nature reviews Neuroscience 14, 383-400.

Paul, L.K. (2011). Developmental malformation of the corpus callosum: a review of typical callosal development and examples of developmental disorders with callosal involvement. Journal of neurodevelopmental disorders 3, 3-27.

Planaguma, J., Haselmann, H., Mannara, F., Petit-Pedrol, M., Grunewald, B., Aguilar, E., Ropke, L., Martin-Garcia, E., Titulaer, M.J., Jercog, P., et al. (2016). Ephrin-B2 prevents N-methyl-Daspartate receptor antibody effects on memory and neuroplasticity. Annals of neurology 80, 388400.

Robichaux, M.A., Chenaux, G., Ho, H.Y., Soskis, M.J., Greenberg, M.E., Henkemeyer, M., and Cowan, C.W. (2016). EphB1 and EphB2 intracellular domains regulate the formation of the corpus callosum and anterior commissure. Developmental neurobiology 76, 405-420.

Rodriguez-Tornos, F.M., Briz, C.G., Weiss, L.A., Sebastian-Serrano, A., Ares, S., Navarrete, M., Frangeul, L., Galazo, M., Jabaudon, D., Esteban, J.A., et al. (2016). Cux1 Enables Interhemispheric Connections of Layer II/III Neurons by Regulating Kv1-Dependent Firing. Neuron 89, 494-506.

Sans, N.A., Montcouquiol, M.E., and Raymond, J. (2000). Postnatal developmental changes in AMPA and NMDA receptors in the rat vestibular nuclei. Brain research Developmental brain research 123, 41-52.

Sheffler-Collins, S.I., and Dalva, M.B. (2012). EphBs: an integral link between synaptic function and synaptopathies. Trends in neurosciences 35, 293-304.

Sheng, M., Cummings, J., Roldan, L.A., Jan, Y.N., and Jan, L.Y. (1994). Changing subunit composition of heteromeric NMDA receptors during development of rat cortex. Nature 368, 144147.

Suarez, R., Fenlon, L.R., Marek, R., Avitan, L., Sah, P., Goodhill, G.J., and Richards, L.J. (2014). Balanced interhemispheric cortical activity is required for correct targeting of the corpus callosum. Neuron 82, 1289-1298.

Takasu, M.A., Dalva, M.B., Zigmond, R.E., and Greenberg, M.E. (2002). Modulation of NMDA receptor-dependent calcium influx and gene expression through EphB receptors. Science 295, 491495.

Traynelis, S.F., Wollmuth, L.P., McBain, C.J., Menniti, F.S., Vance, K.M., Ogden, K.K., Hansen, K.B., Yuan, H., Myers, S.J., and Dingledine, R. (2010). Glutamate receptor ion channels: structure, regulation, and function. Pharmacological reviews 62, 405-496.

Uttl, L., Petrasek, T., Sengul, H., Svojanovska, M., Lobellova, V., Vales, K., Radostova, D., Tsenov, G., Kubova, H., Mikulecka, A., et al. (2018). Chronic MK-801 Application in Adolescence and Early Adulthood: A Spatial Working Memory Deficit in Adult Long-Evans Rats But No Changes in the Hippocampal NMDA Receptor Subunits. Frontiers in pharmacology 9, 42.

Vearing, C.J., and Lackmann, M. (2005). "Eph receptor signalling; dimerisation just isn't enough". Growth factors 23, 67-76.

Vogt, D., Wu, P.R., Sorrells, S.F., Arnold, C., Alvarez-Buylla, A., and Rubenstein, J.L. (2015). Viral-mediated Labeling and Transplantation of Medial Ganglionic Eminence (MGE) Cells for In Vivo Studies. Journal of visualized experiments : JoVE.

Wang, C.L., Zhang, L., Zhou, Y., Zhou, J., Yang, X.J., Duan, S.M., Xiong, Z.Q., and Ding, Y.Q. (2007). Activity-dependent development of callosal projections in the somatosensory cortex. The Journal of neuroscience : the official journal of the Society for Neuroscience 27, 11334-11342.

Weilinger, N.L., Lohman, A.W., Rakai, B.D., Ma, E.M., Bialecki, J., Maslieieva, V., Rilea, T., Bandet, M.V., Ikuta, N.T., Scott, L., et al. (2016). Metabotropic NMDA receptor signaling couples Src family kinases to pannexin-1 during excitotoxicity. Nature neuroscience 19, 432-442.

Wu, J., Zou, H., Strong, J.A., Yu, J., Zhou, X., Xie, Q., Zhao, G., Jin, M., and Yu, L. (2005). Bimodal effects of MK-801 on locomotion and stereotypy in C57BL/6 mice. Psychopharmacology 177, 256-263. 
Yabut, O.R., Fernandez, G., Huynh, T., Yoon, K., and Pleasure, S.J. (2015). Suppressor of Fused Is Critical for Maintenance of Neuronal Progenitor Identity during Corticogenesis. Cell reports 12, 2021-2034.

Yang, J.W., Hanganu-Opatz, I.L., Sun, J.J., and Luhmann, H.J. (2009). Three patterns of oscillatory activity differentially synchronize developing neocortical networks in vivo. The Journal of neuroscience : the official journal of the Society for Neuroscience 29, 9011-9025.

Zhou, J., Wen, Y., She, L., Sui, Y.N., Liu, L., Richards, L.J., and Poo, M.M. (2013). Axon position within the corpus callosum determines contralateral cortical projection. Proceedings of the National Academy of Sciences of the United States of America 110, E2714-2723.

Zuo, D.Y., Zhang, Y.H., Cao, Y., Wu, C.F., Tanaka, M., and Wu, Y.L. (2006). Effect of acute and chronic MK-801 administration on extracellular glutamate and ascorbic acid release in the prefrontal cortex of freely moving mice on line with open-field behavior. Life sciences 78, 2172-2178.

Figures

A
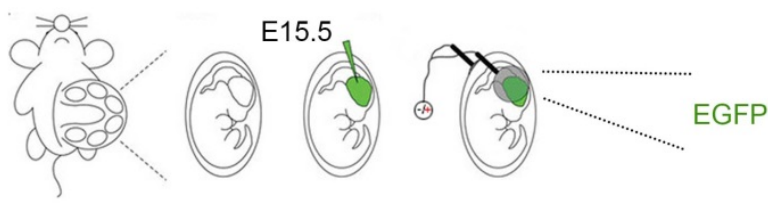

E15.5

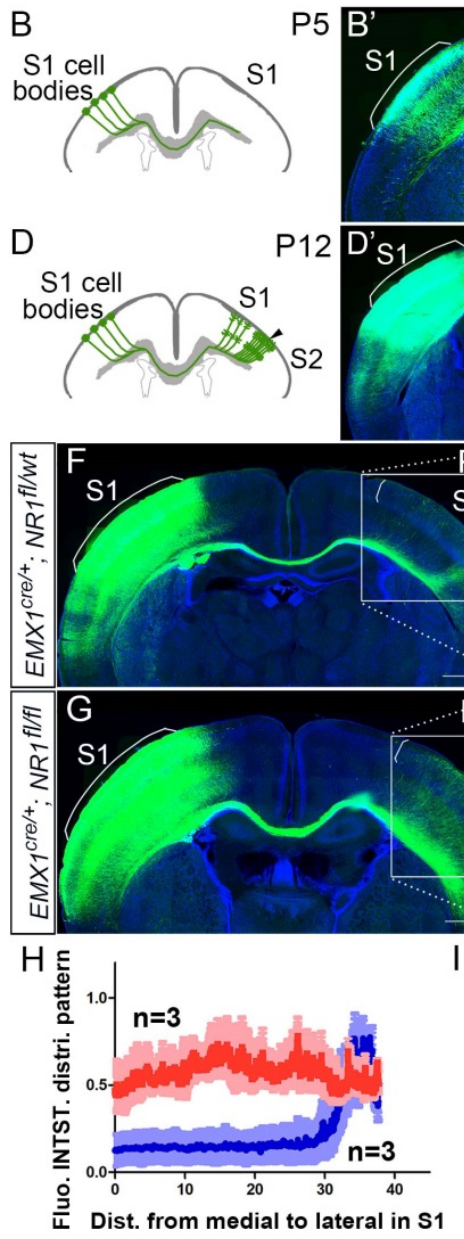

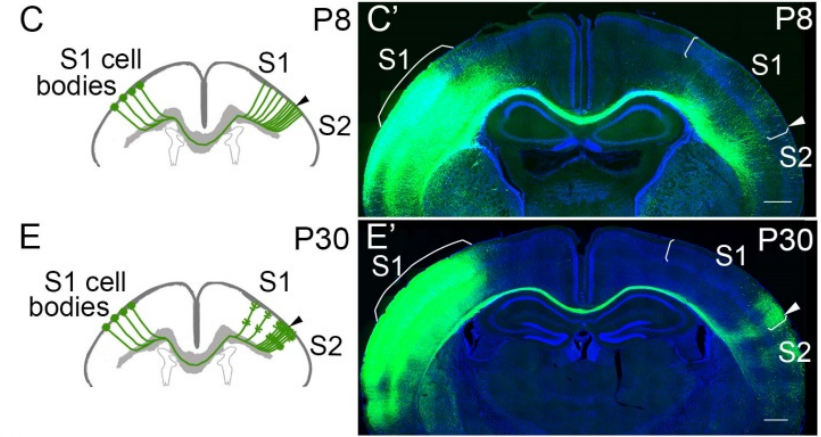
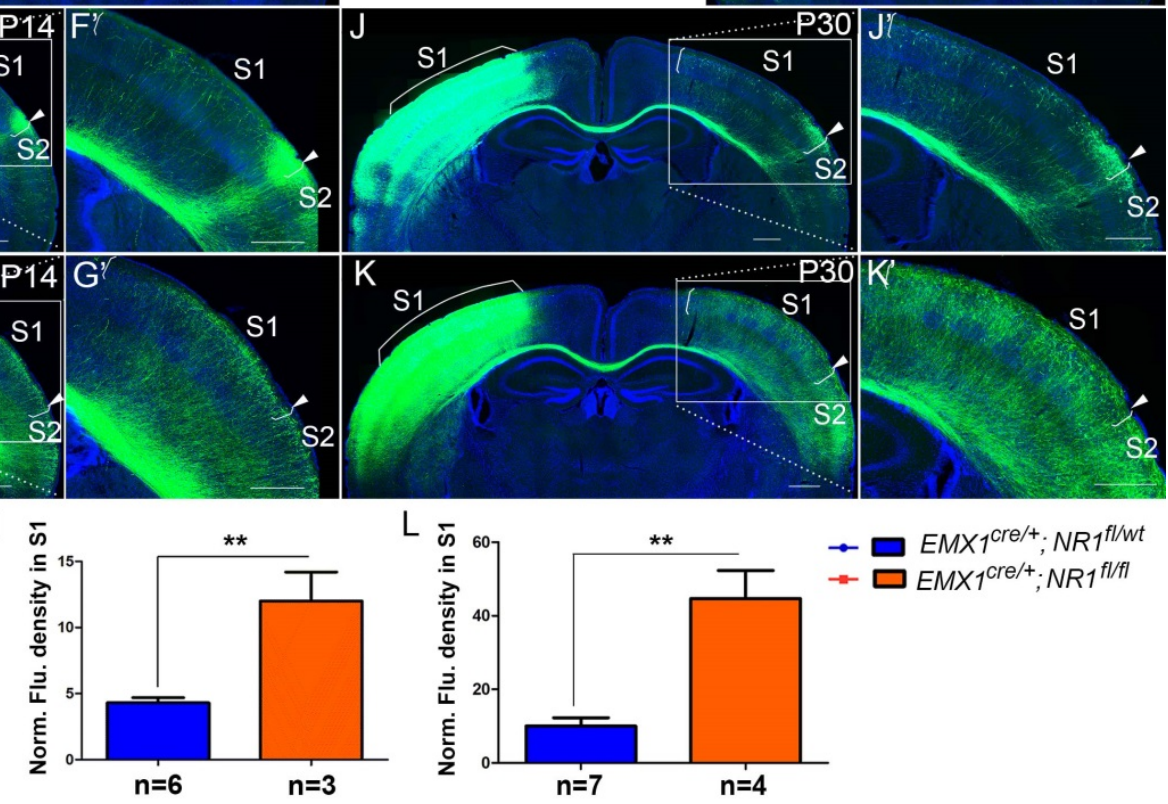
Figure 1: The callosal somatosensory innervation pattern was disrupted in $E m x I^{\text {cre/t+}}$; NRI ${ }^{f l f l}$ mice. (A-E) Postnatal development of callosal projection in S1. (A) EGFP plasmid injected into lateral ventricle of embryo at embryonic day15.5 (E15.5) and electrical pulse given to enable the plasmid to enter cortical progenitor cells of layer II/III in the ventricular zone. (B, B') At postnatal day 5 (P5), the callosal axons from S1 had reached the white matter underneath contralateral S1. (C, C') At P8, the callosal axons were diffusely distributed in contralateral S1. (D, D') By P12, pruning of excess projections led to a refined innervation pattern with a narrow band limited to the S1/S2 border. (E, E') After P12, the pattern was stable as observed at P30. (F) In P14 control mice $\left(E m x I^{c r e /+} ; N R 1^{f l / w t}\right)$, the callosal innervation pattern of S1 of the contralateral cortex is welldifferentiated with a dense innervation at S1/S2 border. The pattern persists to P30 (J). (G) In NR1 KO mice $\left(E m x I^{c r e /+} ; N R f^{f l f f}\right)$, the innervation pattern was disrupted and projections were extremely diffuse which also persisted to P30 (K). (H) Quantification of fluorescent intensity across the medial to lateral extent of the S1. (I, L) Quantification of fluorescence density of S1 region of control vs. NR1 KO mice at P14 (I, P $=0.002)$ and P30 (L, P $=0.0003$ ) Scale bar: $500 \mu \mathrm{m}$ for all images. S1: primary somatosensory cortex; S2: secondary somatosensory cortex.
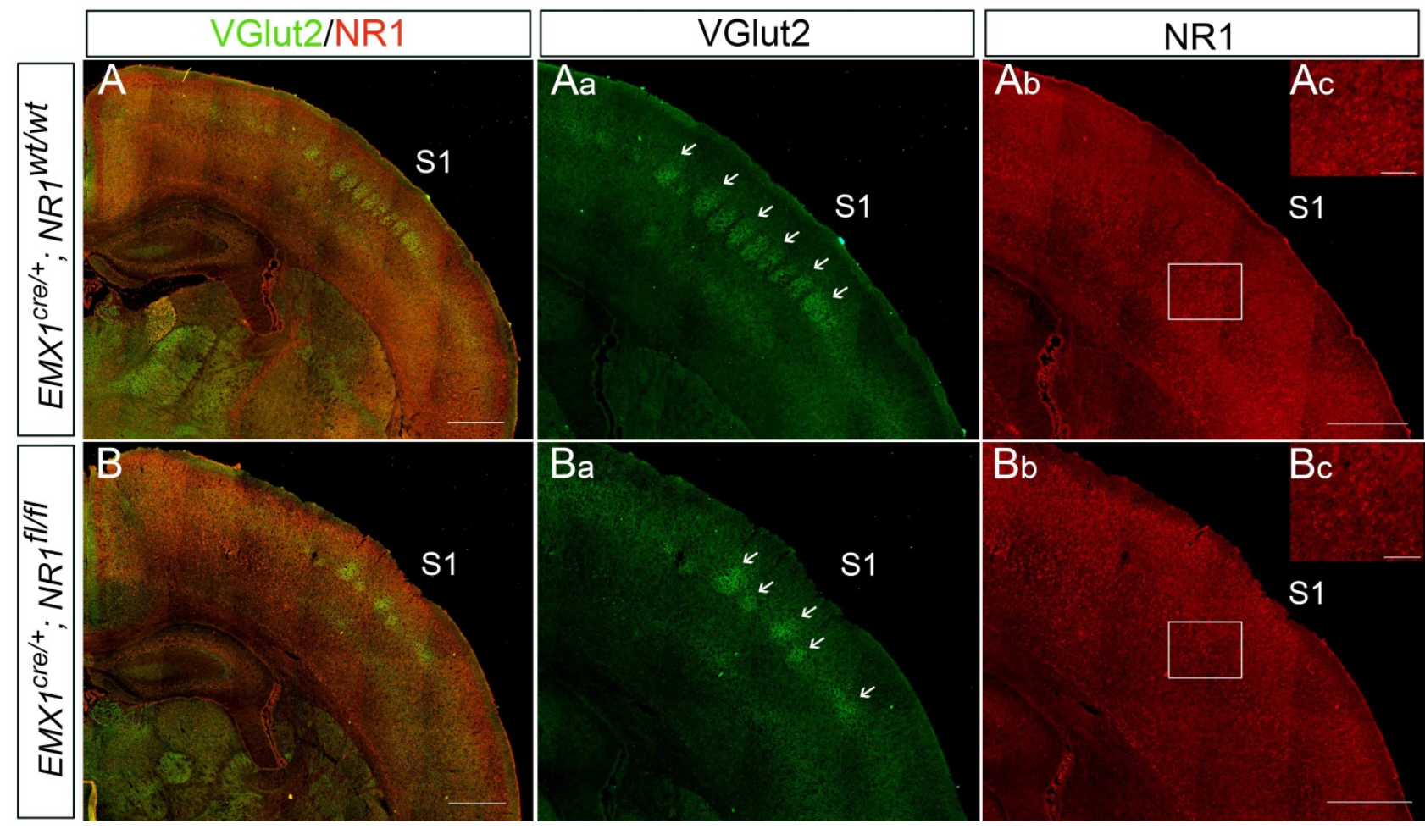

Figure 1-figure supplementary 1: The expression of NMDAR in cortex was reduced in $E m x 1^{\text {cre/t+}}$; $N R I^{f l / f l}$ mice. Examples of $12-\mu \mathrm{m}$ coronal brain sections from P8 $E m x 1^{\text {crel+t}} ; N R I^{w t / w t}$ (A) and $E m x 1^{\text {cre/+ }}$; $N R I^{f l f l}$ (B) of the same litter. Immunostaining of vesicular glutamate transporter 2 (VGult2) showed thalamocortical barrels in Layer IV of S1 which are pointed out by arrows. The VGlut2 staining in $E m x 1^{\text {cre/+}}$; 
$N R I^{w t / w t}$ mice revealed a clear barrel pattern (Aa). However, the barrel pattern in $E m x I^{\text {cre/+}}$; NR $I^{f l f l}$ mice was disrupted and less distinct (Ba). The NR1 staining in $E m x I^{c r e /+} ; N R I^{w t / w t}$ mice were dense and strong in cortex $(\mathrm{Ab}, \mathrm{Ac})$. However, the staining in $E m x I^{c r e /+} ; N R I^{f l f l}$ mice was less bright and apparently reduced in Layer $\mathrm{V}$ and VI (Bb, Bc). Scale bar: $100 \mu \mathrm{m}$ for Ac and Bc; $500 \mu \mathrm{m}$ for rest of images.
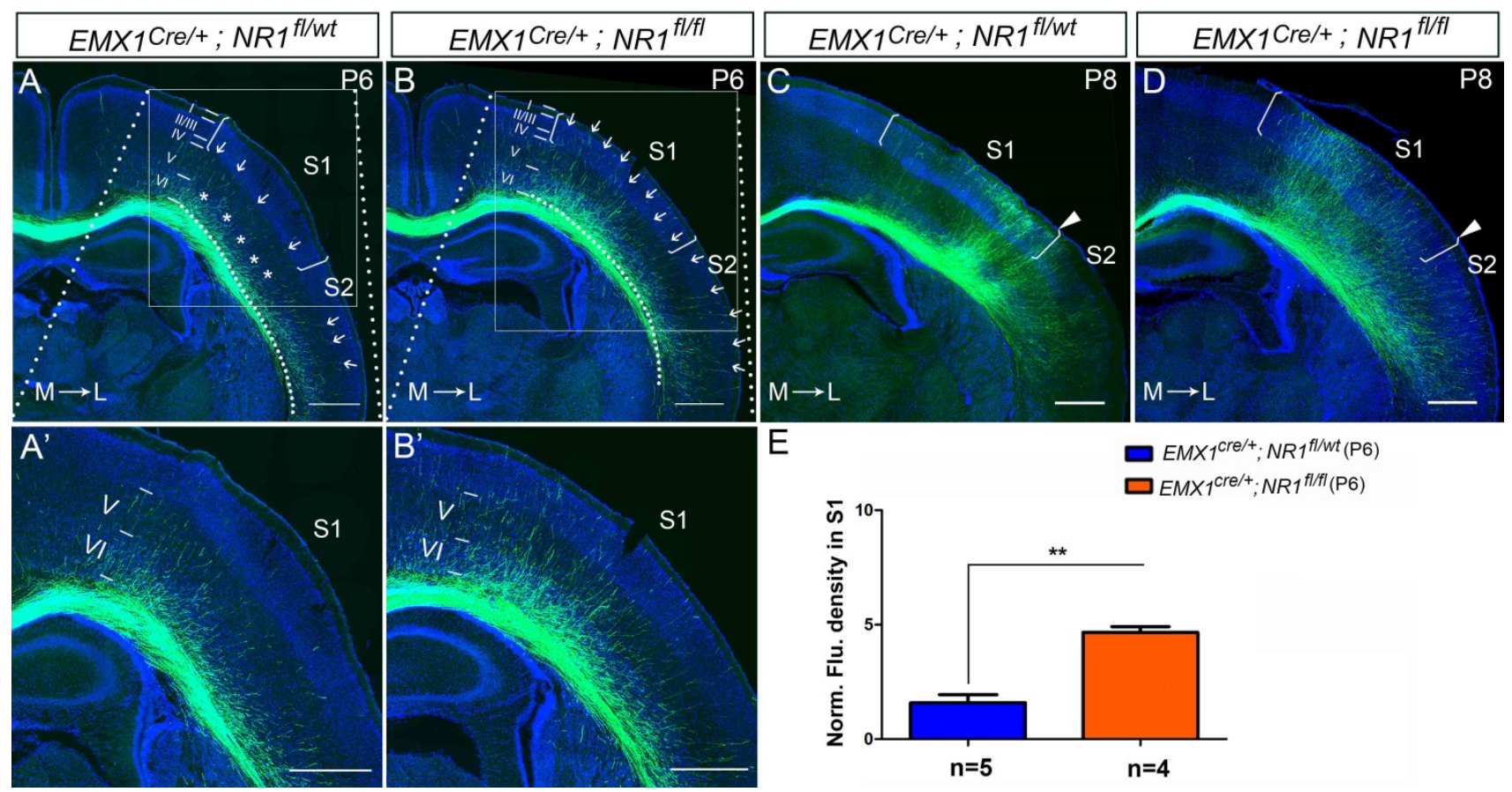

E
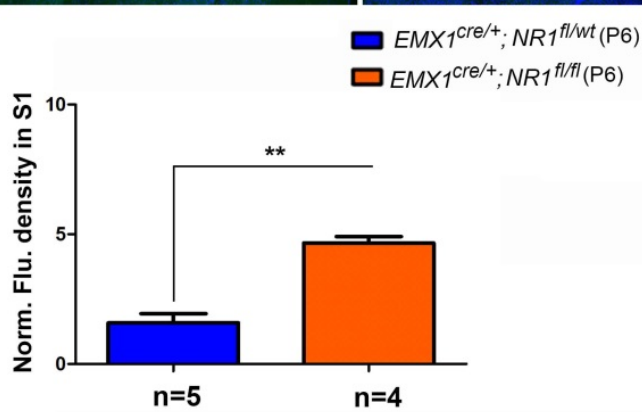

Figure 2: The callosal innervation defect was first detected at $\mathrm{P6}$ in $\boldsymbol{E m x I}^{\text {cre/t }}$; $N R \boldsymbol{I}^{f l / f l}$ mice. (A, A') At P6, most axons in control grew into deeper layer VI of S1 (see “*”); a few axons grew to layer V from medial to lateral S1 (see arrows). However, axons projecting to lateral S2 had grown to layer IV which was apparently faster than the axons in S1 (see arrows). (B, B') In NR1 KO mice, most axons had grown to layer $\mathrm{V}$ and some even grew to layer I (see arrows) at P6. (C, D) At P8, axons in control and mutant mice had grown to the superficial layer of cortex. However, the innervation patterns were different. Controls showed more axon innervation in the lateral S1 with dense callosal innervation at S1/S2 border (C). Mutants showed slightly more axon innervation in the medial S1 (D). (E) The fluorescence density of mutant mice in S1 was significantly higher than in control mice at P6 which suggested that the mutants had increased axon innervation in contralateral $\mathrm{S} 1$ at $\mathrm{P} 6 . \mathrm{P}=0.003$. Scale bar: $500 \mu \mathrm{m}$ for all images. The square brackets in all images outline the S1. The arrow heads in all images outline the S1/S2 border. White lines outline different layers in the cortex of Figure A-D. M: medial; L: lateral. 


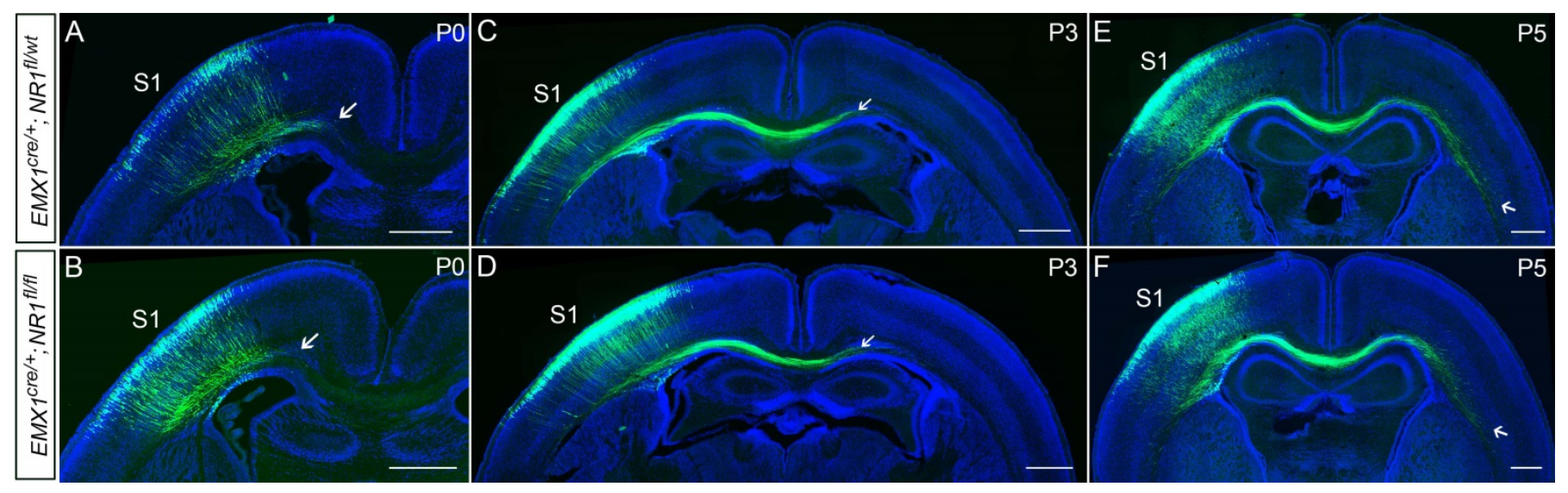

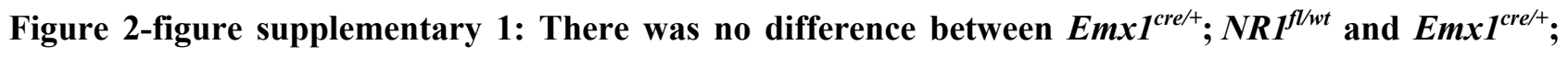
$N R 1^{f l f l}$ mice during axonal extension into the ipsilateral CC (P0) and to the contralateral CC (P5). (A, B) The callosal axons in S1 formed a bundle and grew into the ipsilateral $\mathrm{CC}$ at P0 in control and NR1 KO littermates $\left(E m x I^{c r e /+} ; N R I^{f l / w t}\right.$ and $E m x I^{c r e /+} ; N R I^{f l / f l}$ mice). The arrows show the extent of axon growth into the CC. By P3, the callosal axons crossed the midline (C, D) and by P5, the callosal axons have grown to underneath the contralateral S1 (E, F). Scale bar: $500 \mu \mathrm{m}$ for all images.

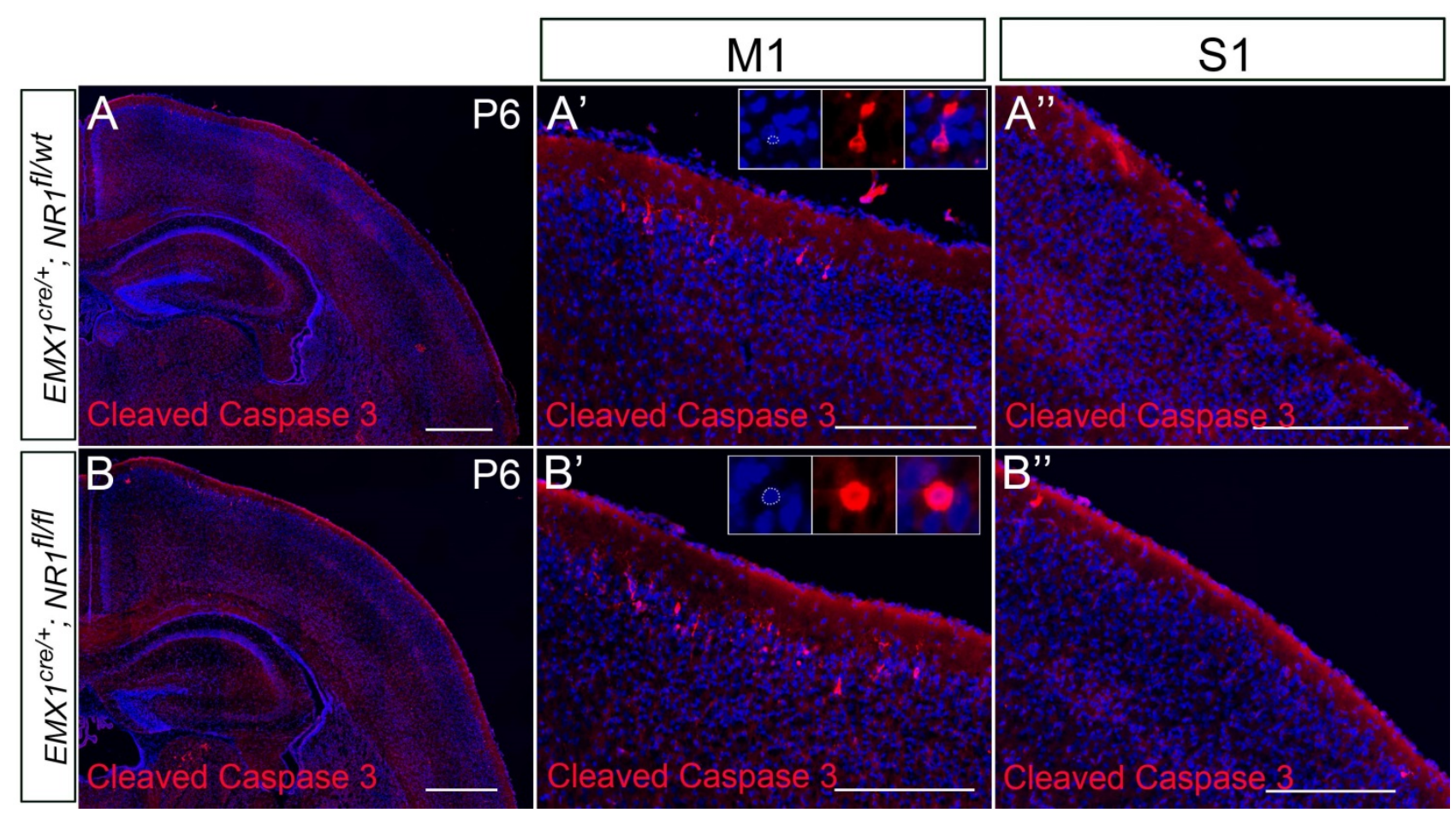

Figure 2-figure supplementary 2: No increased cell death in S1 of $E m x I^{c r e /+}$; NRI ${ }^{f l f l}$ mice at P6. (A) In control mice $\left(E m x I^{c r e /+} ; N R I^{f l / w t}\right)$, cleaved caspase-3 $3^{+}$cells were mostly detected in layer II/III of M1 (A'), 
only rare cell death was observed in other cortical regions, such as S1 (A'). (B) Compared with controls, there was increased cell death in layer II/III of motor cortex in mutant mice $\left(E m x I^{\text {cre/t+ }}\right.$; NR $\left.f^{f l f l}\right)\left(\mathrm{B}^{\prime}\right)$. However, compared with controls, there was no increased cell death in other cortical regions in mutant mice, such as S1 (B'). Scale bar: $500 \mu \mathrm{m}$ for A and B; $200 \mu \mathrm{m}$ for A', A', B' and B'. 
A

$$
\begin{aligned}
& \text { Deleting NMDAR specifically } \\
& \text { in projecting neurons }
\end{aligned}
$$
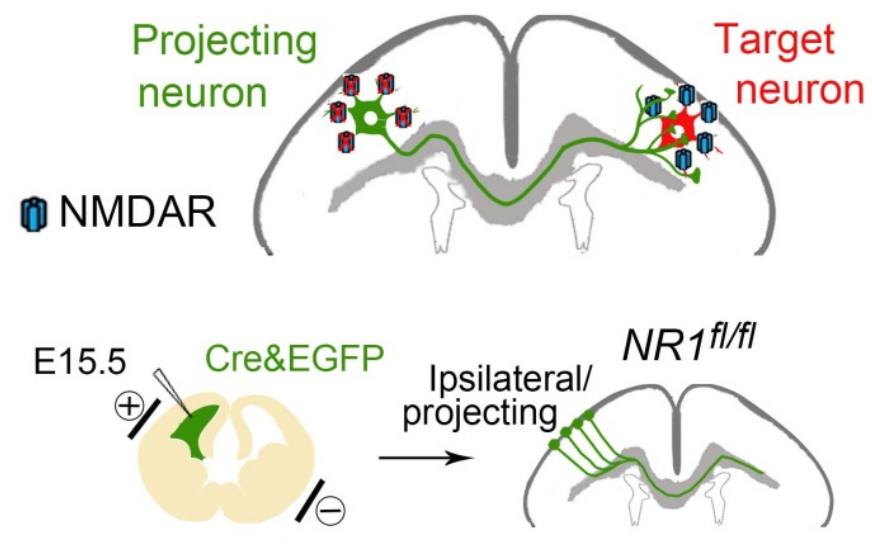

$E$

(17) NMDAR

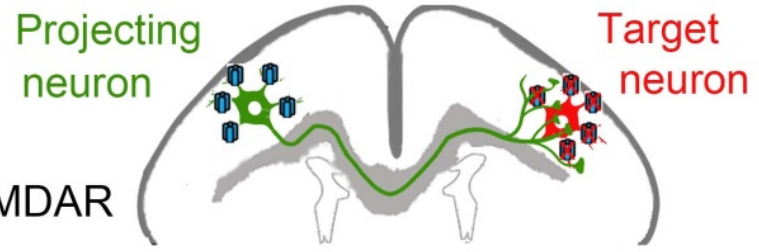

$\mathrm{E} 12.5 \mathrm{Cre} / \oplus$

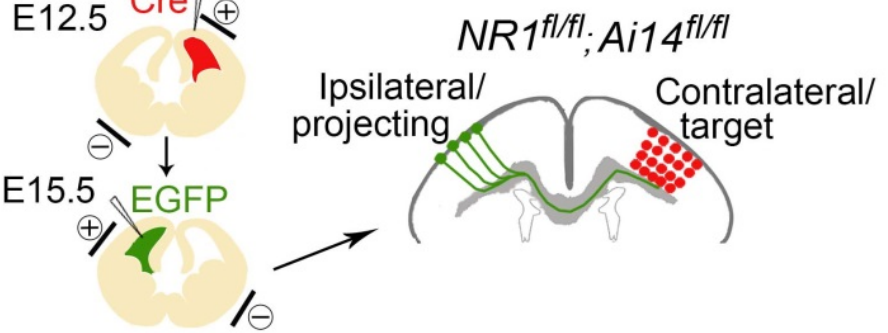

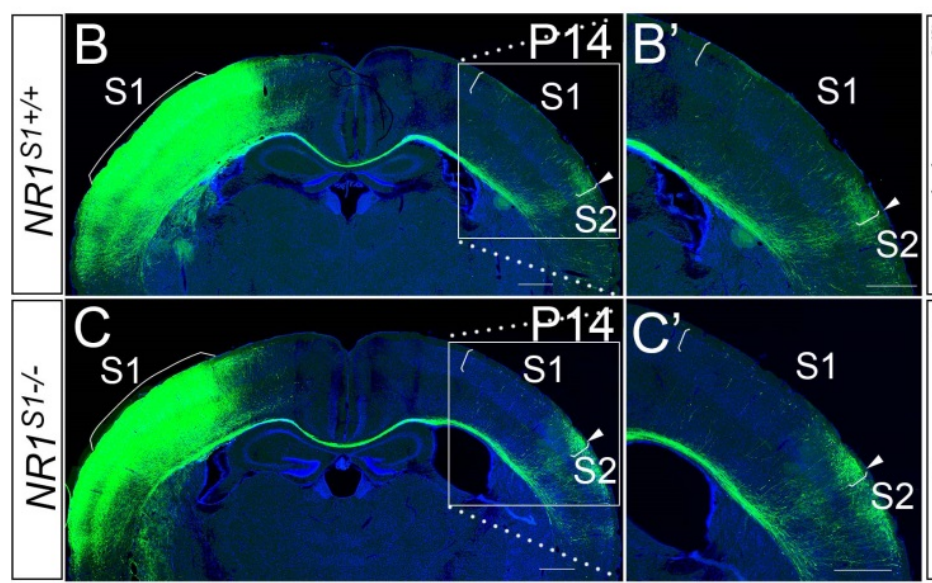

$\mathrm{D}$

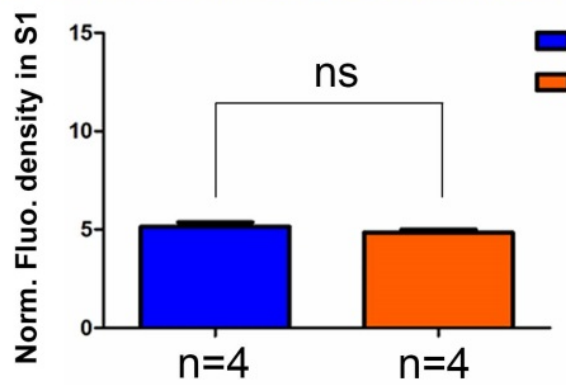

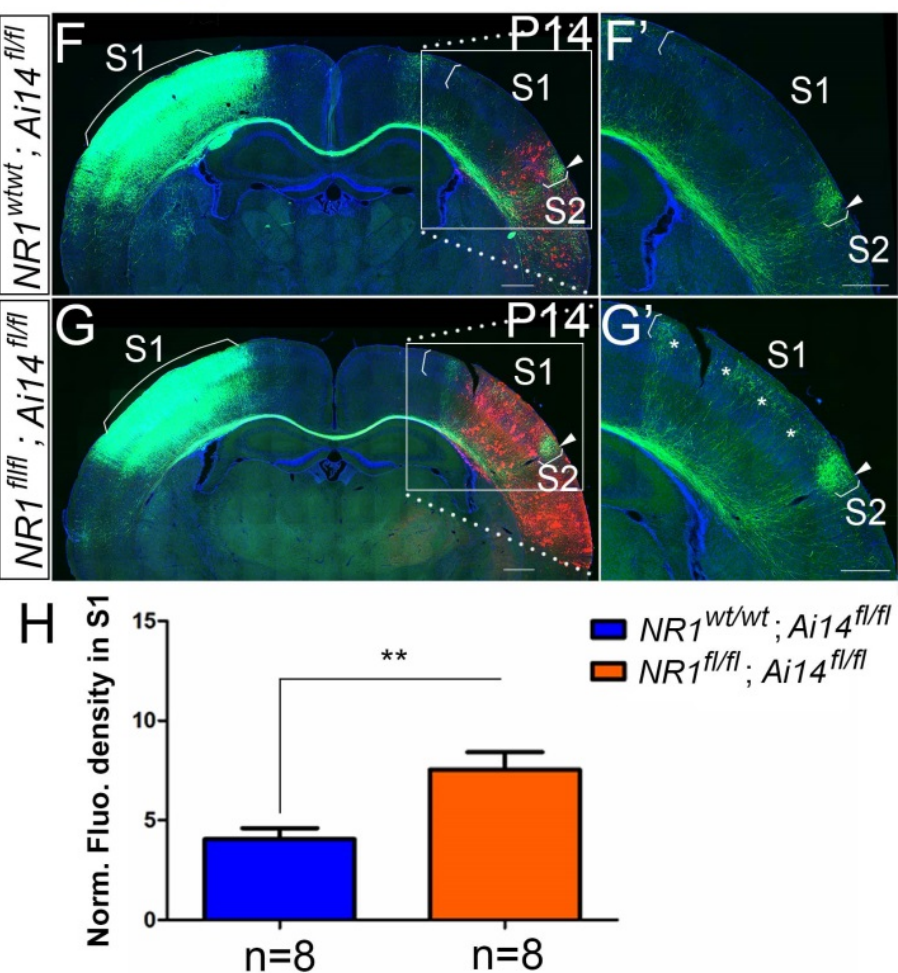

Figure 3: NMDAR is required in target neurons for normal callosal innervation. (A-D) Deleting NMDAR specifically in projecting neurons. Vectors expressing Cre-recombinase (Cre) and EGFP were delivered into S1 of floxed NR1 mice $\left(N R 1^{f l / w t} \mathrm{x} N R f^{f l / w t}\right)$ by in utero electroporation at E15.5 (A). Callosal innervation patterns at $\mathrm{P} 14$ in control $N R I^{i p s i S I+/+}$ mice (B) and $N R I^{i p s i S I-/-}$ mice (C). (D) Quantification of fluorescence density. $\mathrm{P}=$ 0.317. (E-H) Deleting NMDAR specifically in target neurons. NR1 was deleted in target contralateral S1 by in utero electroporation of Cre at E12.5 in $N R 1^{f l f l}$; Ail $4^{f l / f l}$ mice, the ipsilateral projecting neurons were labeled by

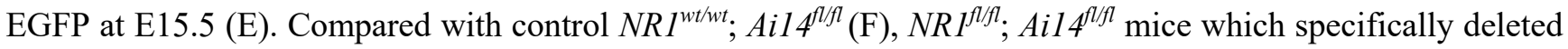


NR1 in target S1 showed increased callosal innervation in S1 as "*” shows $(\mathrm{G})$. (H) Quantification of fluorescence density. $\mathrm{P}=0.002$. Scale bar: $500 \mu \mathrm{m}$ for all images.
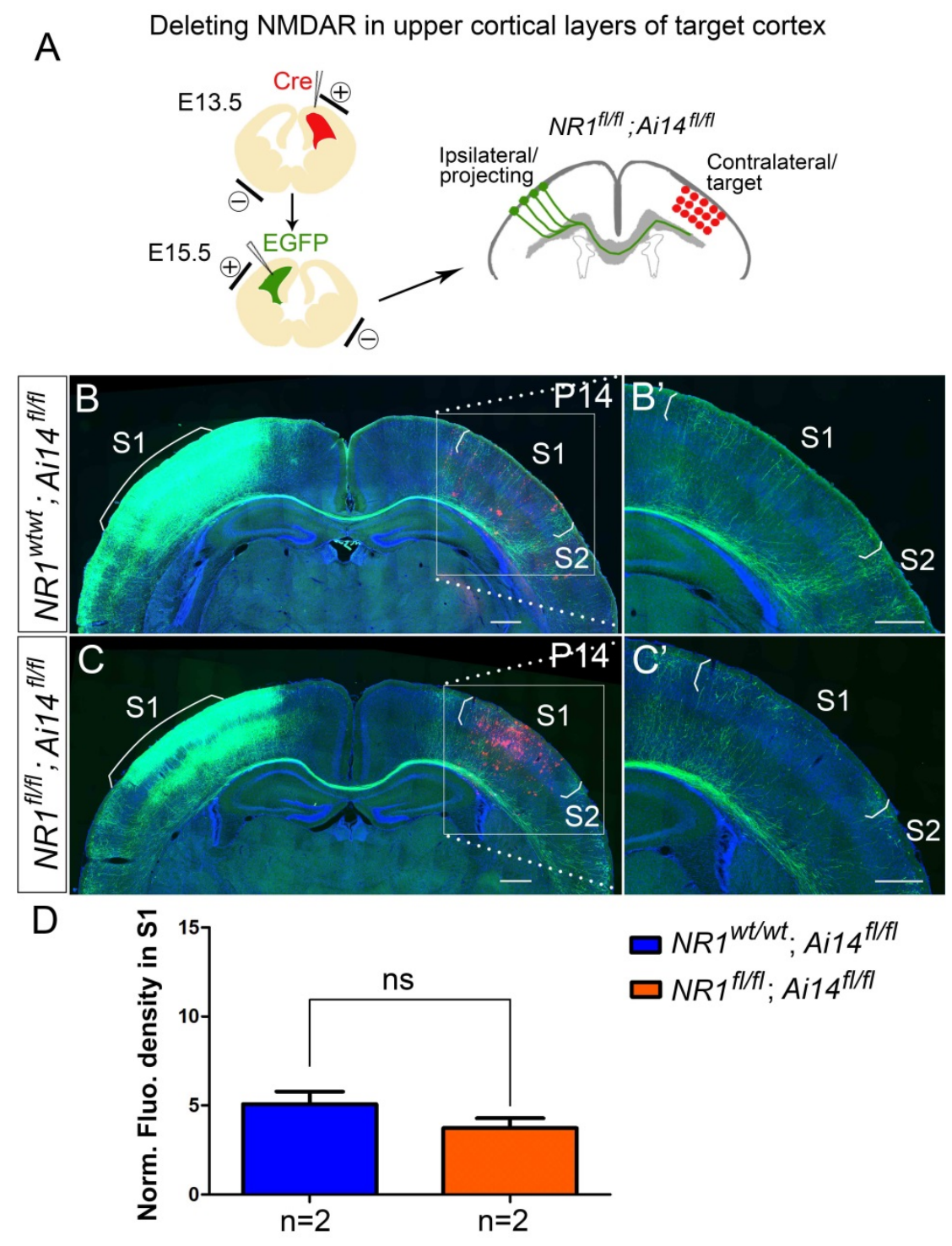

Figure 3-figure supplementary 1: Deleting NMDAR in upper contralateral cortical layers had no effect on callosal innervation pattern of S1 at P14. (A) NR1 was deleted in target contralateral S1 by in utero electroporation of Cre at E13.5 in NR $1^{f l f l}$; Ai14 $4^{f l f l}$ mice, the ipsilateral projecting neurons were labeled by EGFP at E15.5. Compared with control NRI $1^{w t / w t} ; A i 14^{f l f l}(\mathrm{~B}), N R 1^{f l f f}$; $A i 14^{f l / f l}$, with NR1 specifically deleted in upper cortical layers did not show increased callosal innervation in (C). (D) Quantification of fluorescence density. $\mathrm{P}=$ 0.27 . Scale bar: $500 \mu \mathrm{m}$ for all images. 

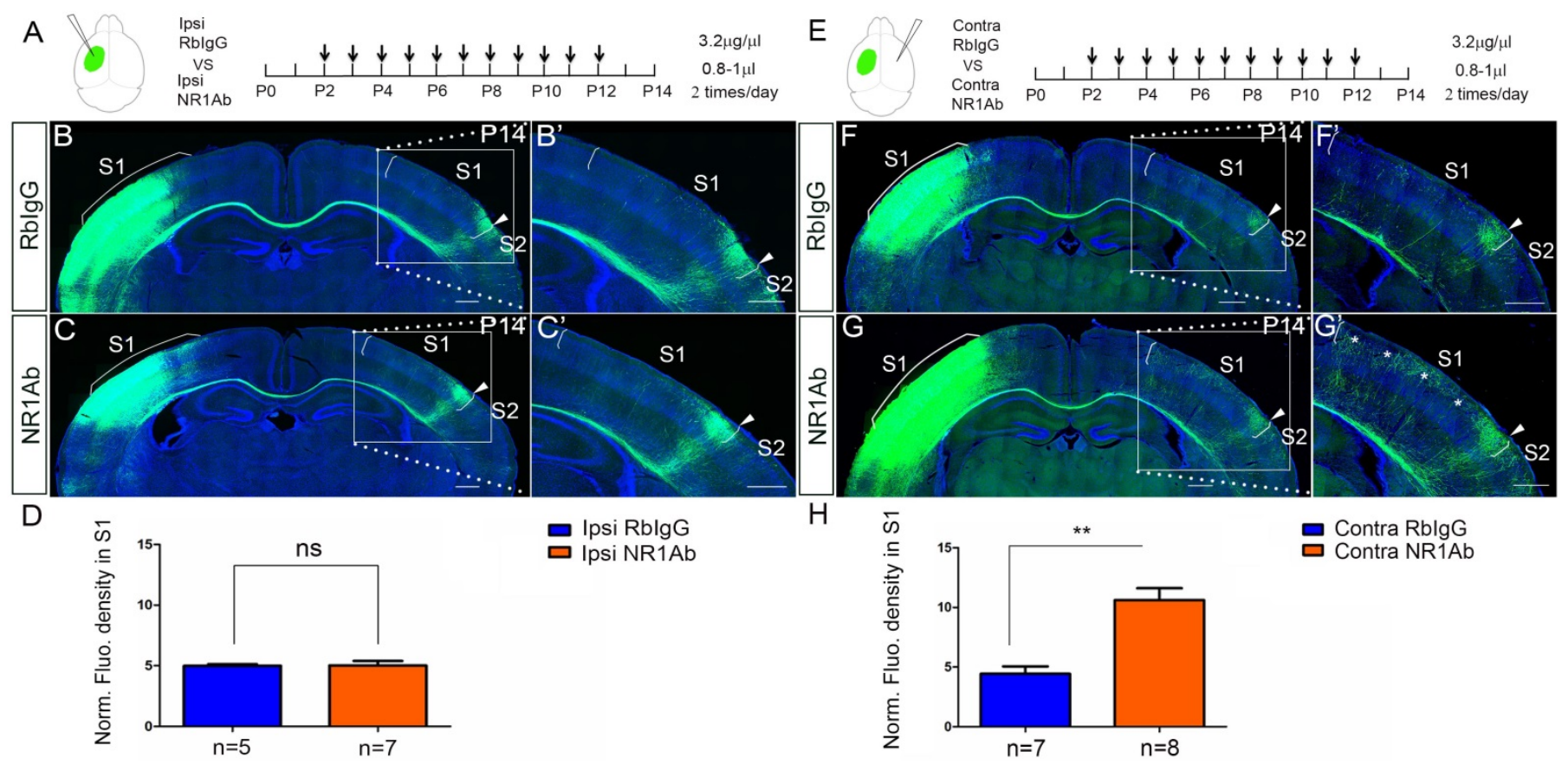

Figure 4: Increased callosal innervation in $\mathrm{S} 1$ after contralateral but not ipsilateral injection of antiNMDAR antibodies from P2 to P12. (A-D) Anti-NR1 antibodies were injected into the lateral ventricle from P2 to P12 in ipsilateral cortex. RbIgG served as control. Compared with control (B), antibody injection in mice did not show increased callosal innervation in S1 at P14 (C). (D) Quantification of fluorescence density. P = 0.94. (E-H) Anti-NR1 antibodies were injected into the lateral ventricle from P2 to P12 in contralateral cortex. Compared with control (F), antibody injection in mice showed increased callosal innervation in S1 at P14 (see “*”, G). (H) Quantification of fluorescence density. $\mathrm{P}=0.0002$. Scale bar: $500 \mu \mathrm{m}$ for all images. 


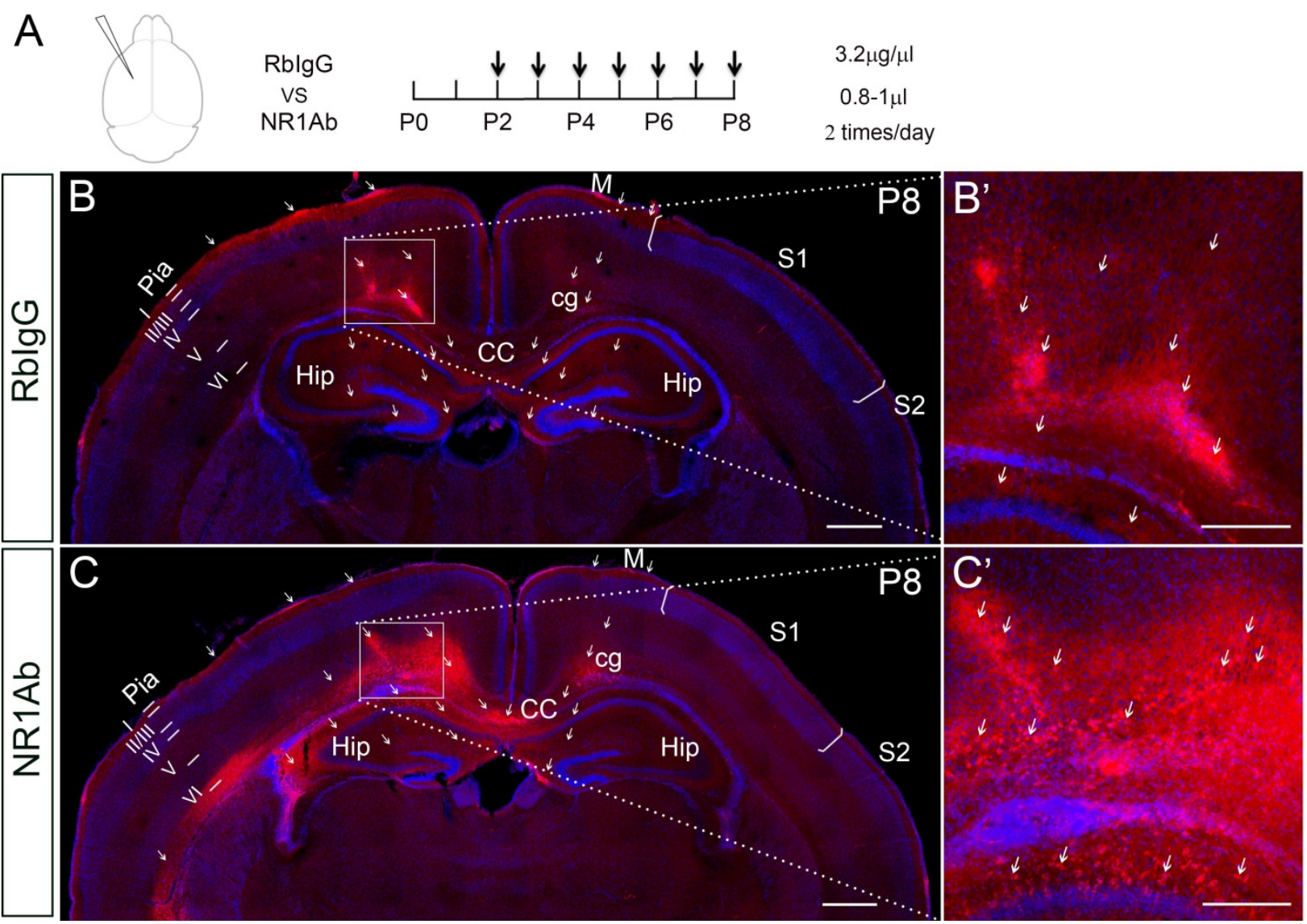

Figure 4-figure supplementary 1: The efficiency of intraventricular antibody injection and the distribution territory in the cortex after $3 \mathrm{hr}$ of last injection. (A) Anti-NR1 antibodies were injected into the lateral ventricle from P2 to P8 and mice were perfused 3 hours later after last injection. Rabbit IgG served as control. Mouse brains then were stained with anti-Rabbit secondary coupled to Alexa594. The red fluorophore of Alexa594 indicated where the antibodies had distributed to. Scale bar: $500 \mu \mathrm{m}$ for all images. (B, B') In control, the fluorescence signals were mostly detected in the cortex of the ipsilateral injection side, and few in the contralateral cortex. In the ipsilateral injection side, the signals were detected in all the cortical layers, but most strongly in the pia, layer I, layer V, layer VI, cingulum and corpus callosum (see arrows). The signals were also detected in the hippocampus and contralateral motor cortex (see arrows). (C, C') The general antibody distribution pattern was similar as seen in control. Moreover, the anti-NR1 antibody can bind to NMDAR on the cell membranes, which thus showing beautiful cell membrane staining (see arrows in C'). Scale bar: $500 \mu \mathrm{m}$ for Figure B, C; $200 \mu \mathrm{m}$ for Figure B', C'. CC: corpus callosum; cg: cingulum; Hip: hippocampus; M: motor cortex; S1: primary somatosensory cortex; S2: secondary somatosensory cortex. 


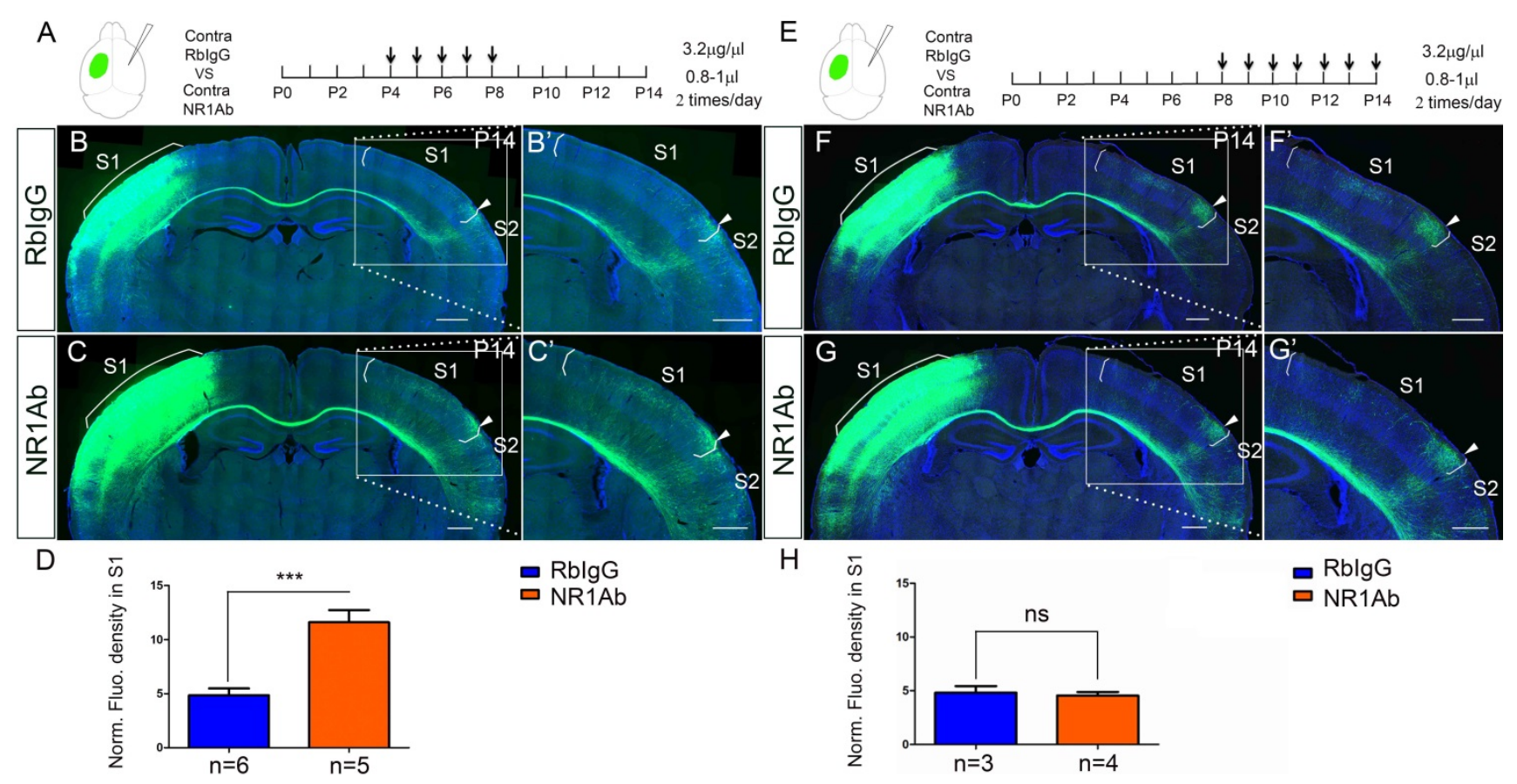

Figure 5: Contralateral injection of anti-NMDAR antibodies from P4 to P8 but not P8 to P14 had increased callosal innervation in S1. (A-D) Anti-NR1 antibodies were injected into the lateral ventricle from P4 to P8 in contralateral cortex. RbIgG served as control. Compared with control (B), antibody injection in mice show increased callosal innervation in S1 at P14 (C). (D) Quantification of fluorescence density. P=0.004. (EH) Anti-NR1 antibodies were injected into the lateral ventricle from P8 to P14 in contralateral cortex. Compared with control (F), antibody injection in mice did not show increased callosal innervation in S1 at P14 (G). (H) Quantification of fluorescence density. $\mathrm{P}=0.69$. Scale bar: $500 \mu \mathrm{m}$ for all images. 

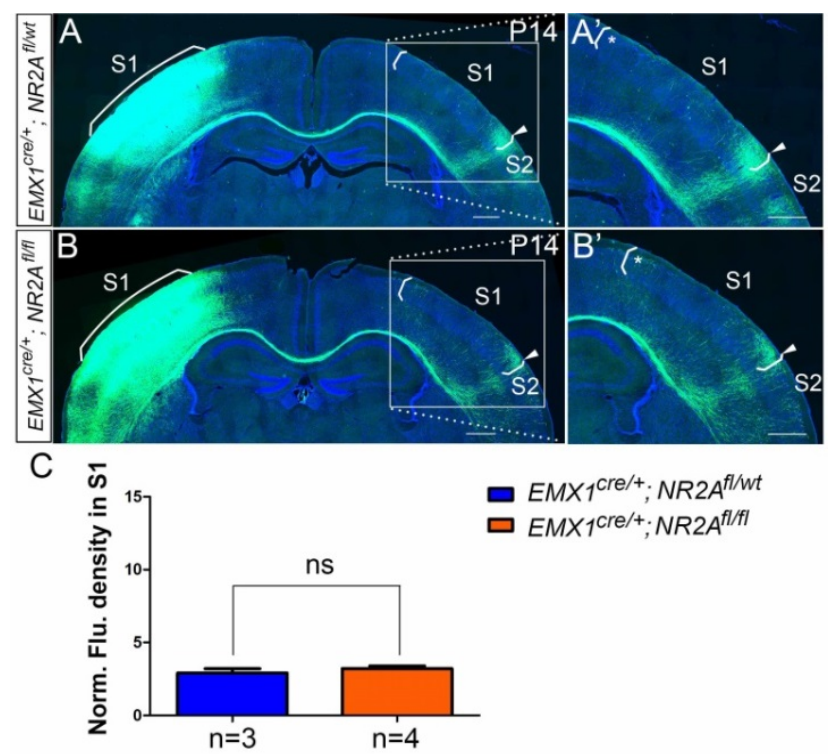
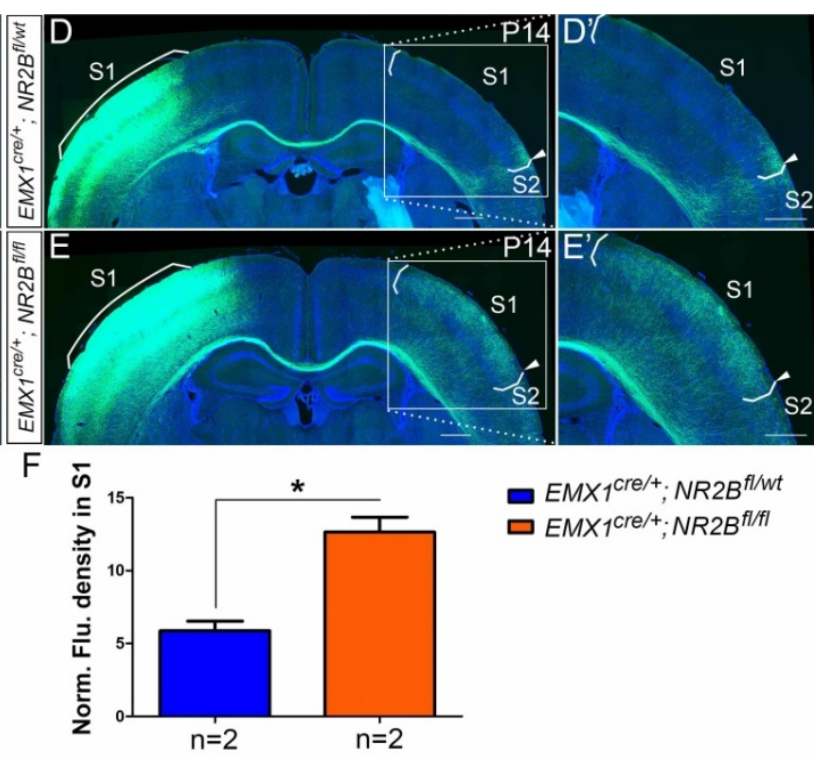

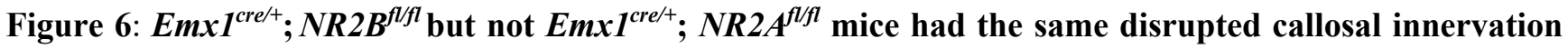

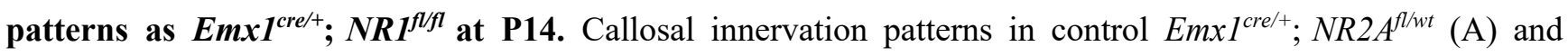
$E m x 1^{\text {cre/t }}$;NR2 $A^{f l f l}$ mice (B) at P14. “*” points out M1/S1 border. (C) Quantification of fluorescence density. $\mathrm{P}=$ 0.392. Callosal innervation patterns in control $E m x 1^{\text {cre/+}} ; N R 2 B^{f l / w t}(\mathrm{D})$ and $E m x l^{\text {cre/+}} ; N R 2 B^{f l / f l}$ mice (E) at P14. (F) Quantification of fluorescence density. $\mathrm{P}=0.03$. Scale bar: $500 \mu \mathrm{m}$ for all images.
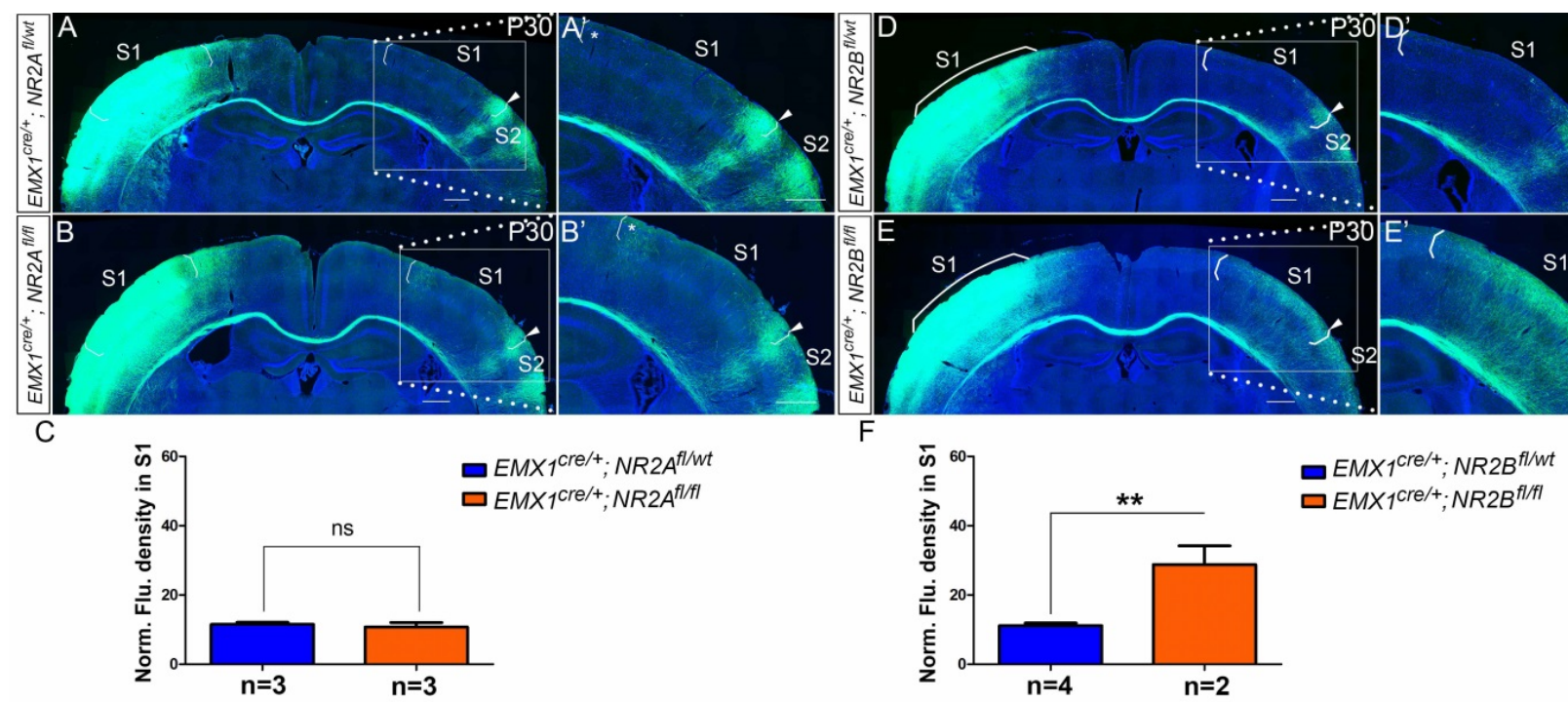

Figure 6-figure supplementary 1: NR2B $\left(E m x 1^{c r e /+} ; N R 2 B^{f l f l}\right)$ but not NR2A $\left(E m x 1^{c r e /+} ; N R 2 A^{f l f l}\right)$ mice had same disrupted callosal innervation patterns as $E m x I^{\text {cre/t+}} ; N R I^{f l f l}$ at P30. (A) The callosal innervation pattern in $\mathrm{S} 1$ at $\mathrm{P} 30$ in control mice $\left(E m x I^{c r e /+} ; N R 2 A^{f l / w t}\right)$ is similar as the pattern in P14 WT control mice, with few axons in $\mathrm{S} 1$ but a dense innervation at $\mathrm{S} 1 / \mathrm{S} 2$ border. (B) In the mutant mice 
$\left(E m x 1^{c r e /+} ; N R 2 A^{f l f f}\right)$, the general innervation pattern was as same as control. However, the increased callosal innervation at the border of M1 and S1 was persistent at P30 (see “*” in B'). (C) Quantification of fluorescence density. $\mathrm{P}=0.63$. (D) In control $E m x I^{\text {cre/t+}} ; N R 2 B^{f / / w t}$ mice, the callosal innervation pattern at P30 was as normal as WT control. (E) However, the increased callosal innervation in $E m x 1^{\text {cre/+}} ; N R 2 B^{\mathrm{fl} / \mathrm{fl}}$ mice lasted at least to P30 as we observed in $E m x I^{\text {cre/+}} ; N R I^{f l f l}$ mice at P30. (F) Quantification of fluorescence density. $\mathrm{P}=0.007$. Scale bar: $500 \mu \mathrm{m}$ for all images.
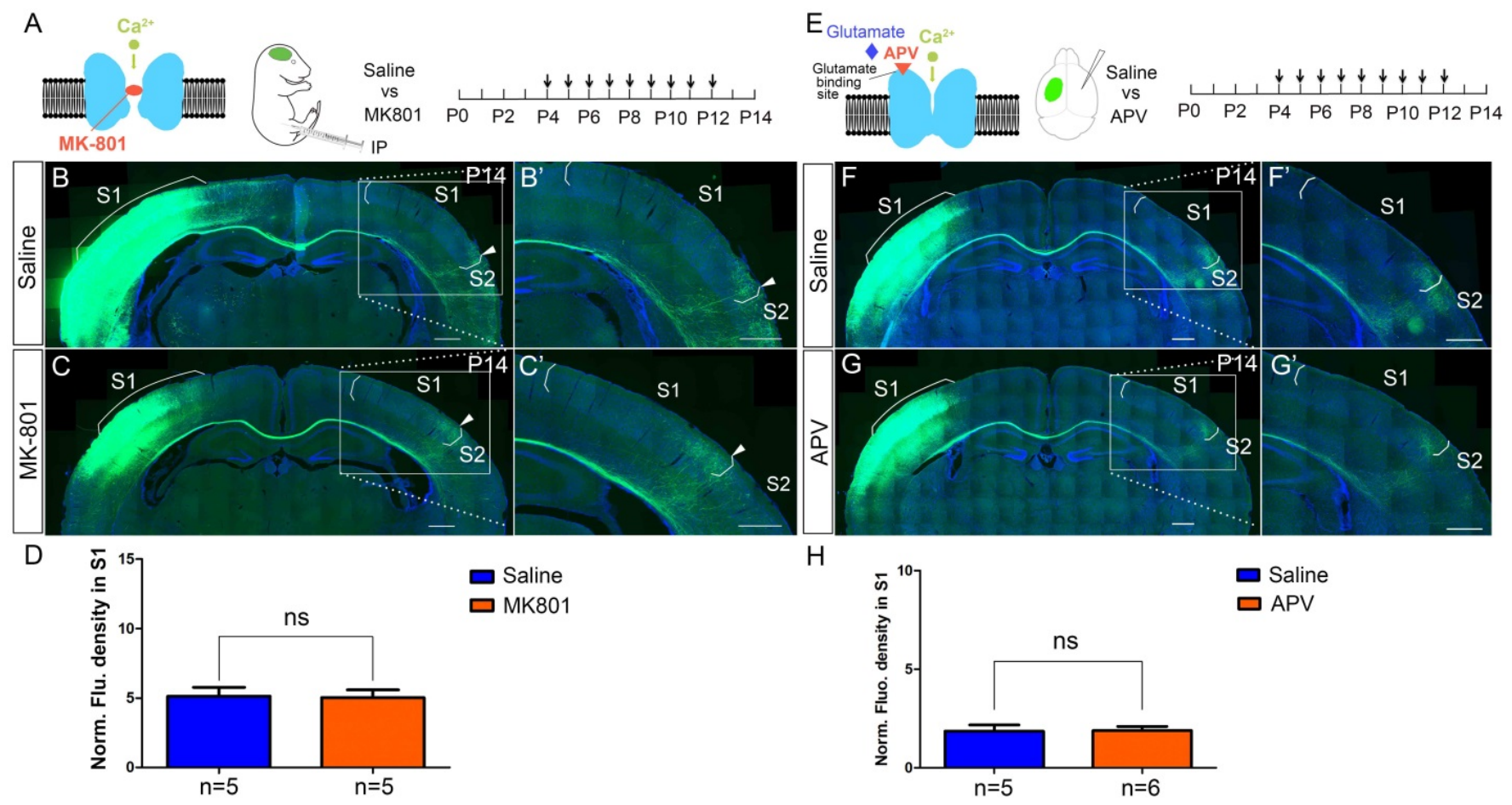

Saline $\square$ MK801

$\mathrm{H}$

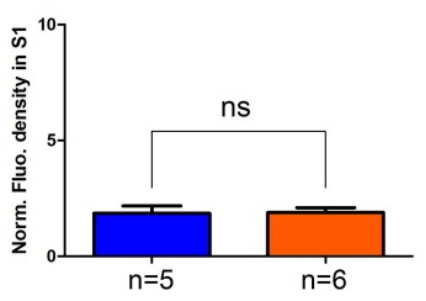

Figure 7: NMDAR regulates callosal circuit development independent of NMDAR channel activity. (A-D) Blocking $\mathrm{Ca}^{2+}$ influx through NMDAR by MK-801. MK-801 enters the open NMDAR channel and binds to the "blocking site" located deep in the pore (A). Callosal innervation patterns in Saline (B) and MK-801 (C) injected mice at P14. (D) Quantification of fluorescence density. P=0.91. (E-H) Blocking NMDAR channel opening by D-APV. D-APV competitively inhibits glutamate binding site to NMDAR (E). Callosal innervation patterns in Saline (F) and D-APV (G) injected mice at P14. (H) Quantification of fluorescence density. P=0.93. Scale bar: $500 \mu \mathrm{m}$ for all images. 
A

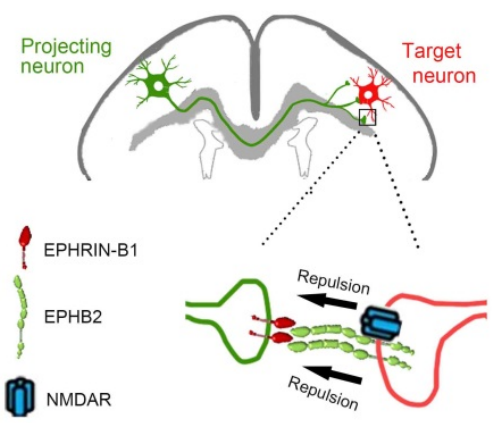

Blocking EPHB function in target neurons by EPHRIN-B1-FC
Deleting Ephrin-B1 specifically in projecting neurons

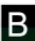

B

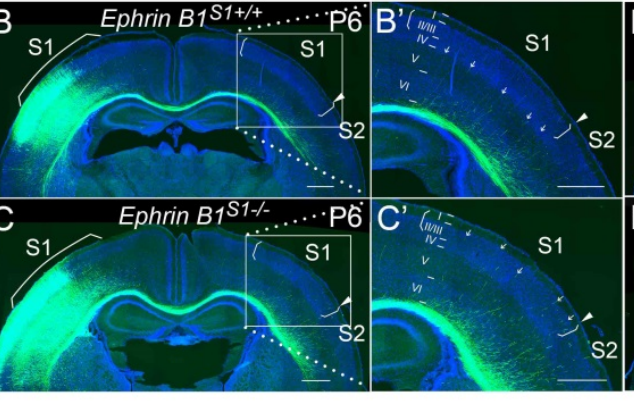

Blocking NMDAR and EPHB function simutaneously by $\mathrm{NR} 1 \mathrm{Ab}$ and EPHRIN-B1-Fc in target neurons

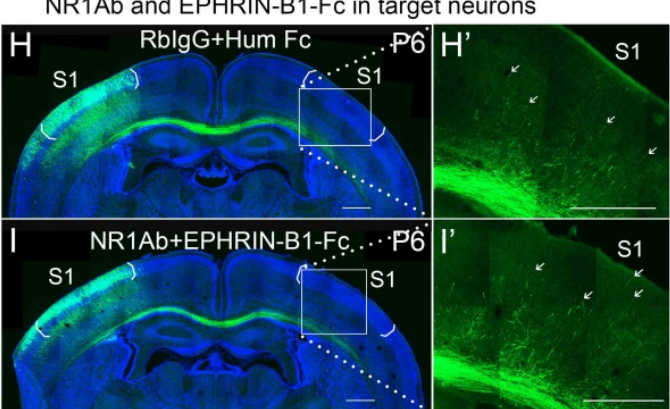

Blocking NMDAR function in target neurons by $\mathrm{NR} 1 \mathrm{Ab}$

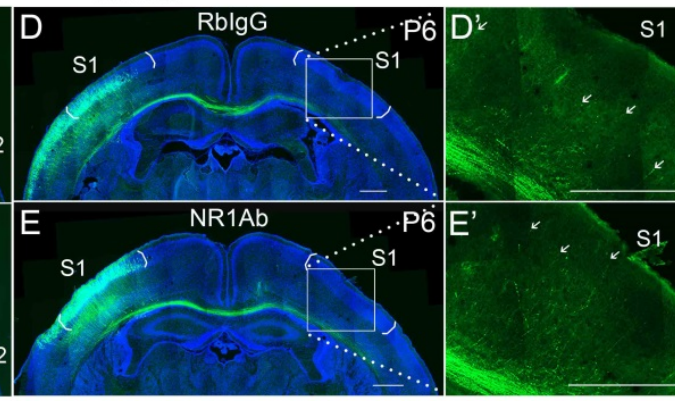

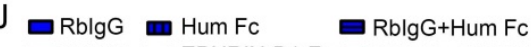
$\square$ NR1Ab 血 EPHRIN-B1-Fc $\boxminus$ NR1Ab+EPHRIN-B1-Fc

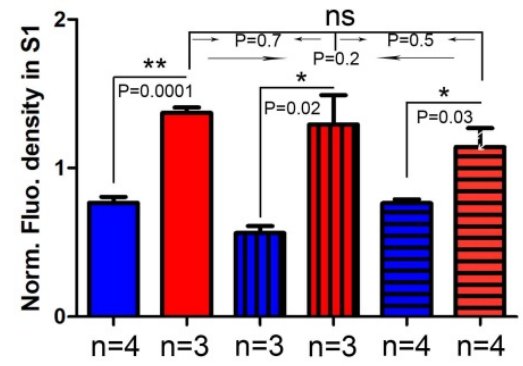

Figure 8: NMDARs cooperate with EPHRIN-B/EPHB in controlling axon targeting in S1. (A) EPHRIN-B1, expressed by the projecting neuronal axons, signals through EPHB2 and NMDAR, located on the target neurons, regulates axon extension in contralateral cortex. $(\mathrm{B}, \mathrm{C})$ Deleting Ephrin-B1 in projecting neurons in EphrinB $1^{f l / f l}$ mice. Vectors expressing Cre and EGFP were delivered into S1 of floxed EphrinB1 mice (EphrinBI $1^{f l / w t} \mathrm{x}$ EphrinB $1^{f l / w t}$ ) by in utero electroporation at E15.5. Compared with control Ephrin B1 $1^{i p s i S 1+/+}$ mice (B), Ephrin $B 1^{\text {ipsis1-- }}$ mice showed earlier callosal innervation at P6 (C). (D, E) Blocking NMDAR function in target neurons by intraventricular injection of NR1Ab in contralateral cortex, from P3 to P6. Compared with control RbIgG injected mice (D), NR1Ab injected mice showed earlier callosal innervation at P6 (E). (F, G) Blocking EPHB function in target neurons by intraventricular injection of EPHRIN-B1-Fc in contralateral cortex, from P3 to P6. Compared with control Hum Fc injected mice, EPHRIN-B1-Fc injected mice showed earlier callosal innervation at P6 (G). (H, I) Blocking NMDAR and EPHB function simultaneously by NR1Ab and EPHRINB1-Fc in contralateral cortex, from P3 to P6. Compared with control RbIgG + Hum IgG injected mice $(\mathrm{H})$, $\mathrm{NR} 1 \mathrm{Ab}+\mathrm{EPHRIN-B1-Fc} \mathrm{injected} \mathrm{mice} \mathrm{showed} \mathrm{earlier} \mathrm{callosal} \mathrm{innervation} \mathrm{at} \mathrm{P6} \mathrm{(I).} \mathrm{(J)} \mathrm{Quantification} \mathrm{of}$ fluorescence density. Scale bar: $500 \mu \mathrm{m}$ for all images. Arrows pointed out axon terminals in the target cortex. 

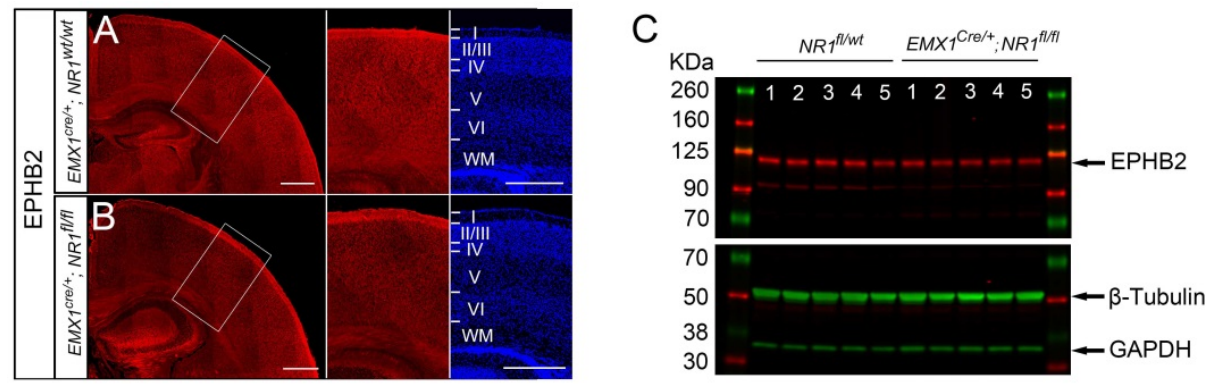

D Relative EPHB2 protein level to $\beta$-Tubulin

E Relative EPHB2 protein level

F Relative mRNA level of EPHB2

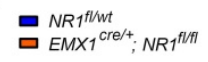
to GAPDH
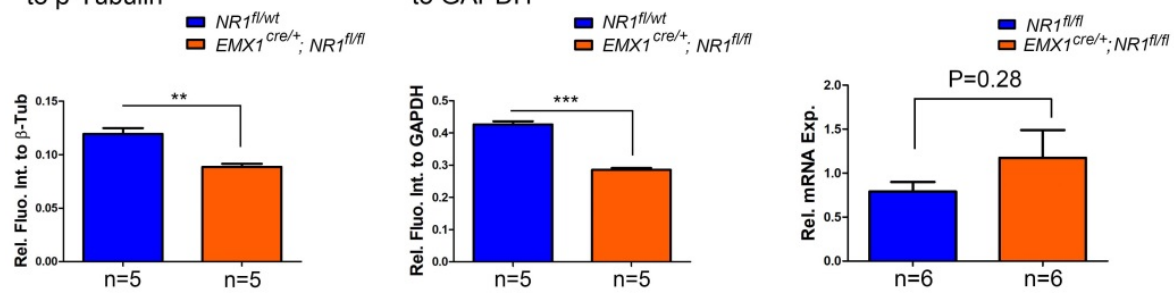

Figure 8-figure supplementary 1: The protein but not RNA level of EPHB2 was reduced in $E m x 1^{\text {cre/t}}$; $N R I^{f l / f l}$ mice at P8. . (A, B) EPHB2 protein expression are decreased in $E m x 1^{\text {cre/+ }} ; N R 1^{f l / f l}$ mice at P5. In control $E m x 1^{c r e /+}$; NR $1^{w t / w t}$ mice, EPHB2 was expressed both in CC and cortex (A). EPHB2 in $E m x 1^{\text {cre } /+}$; $N R I^{f l f l}$ mice was dramatically decreased in cortex (B). (C) Western blot analysis of cortical protein extracts from P8 S1 showed that, relative to the loading control beta-tubulin ( $\beta$-Tub) and GAPDH, lower levels of EPHB2 were observed in the five samples of $E m x I^{c r e /+} ; N R I^{f l / f l}$ mice compared to the five samples of controls. (D) Quantification of protein levels relative to $\beta$-Tub. $P=0.001$. (E) Quantification of protein levels relative to GAPDH. $\mathrm{P}<0.0001$. (F) The quantitative polymerase chain reaction (qPCR) analysis showed no expression difference of EPHB2 between $E m x I^{c r e /+}$; NR $1^{f l / f l}$ mice and controls. Scale bar: $500 \mu \mathrm{m}$ for A, B. 
WT
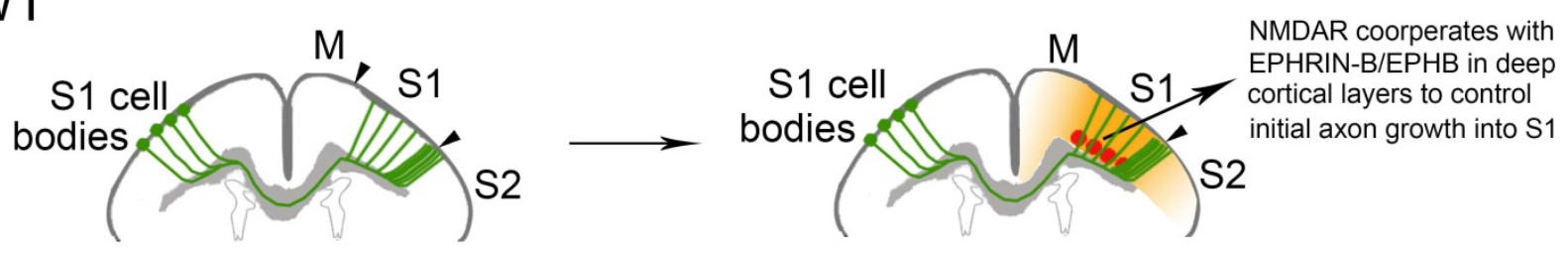

\section{NMDAR KO}
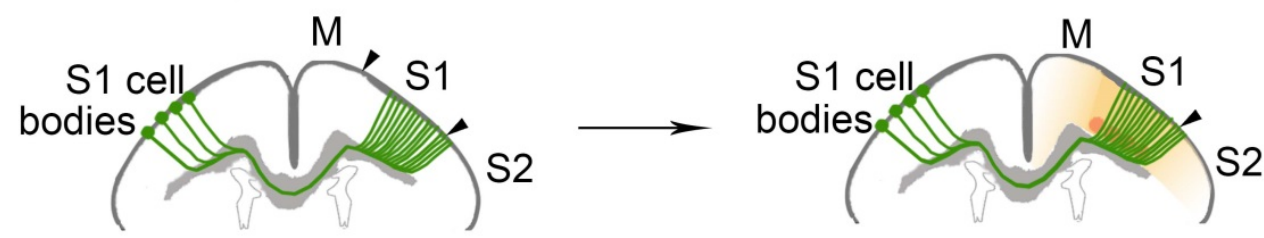

Figure 9: Mechanisms for increased callosal innervation in NMDAR KO mice. NMDARs cooperate with EPHRIN-B/EPHB signaling in deep cortical layers to regulate axon extension into the cortex.

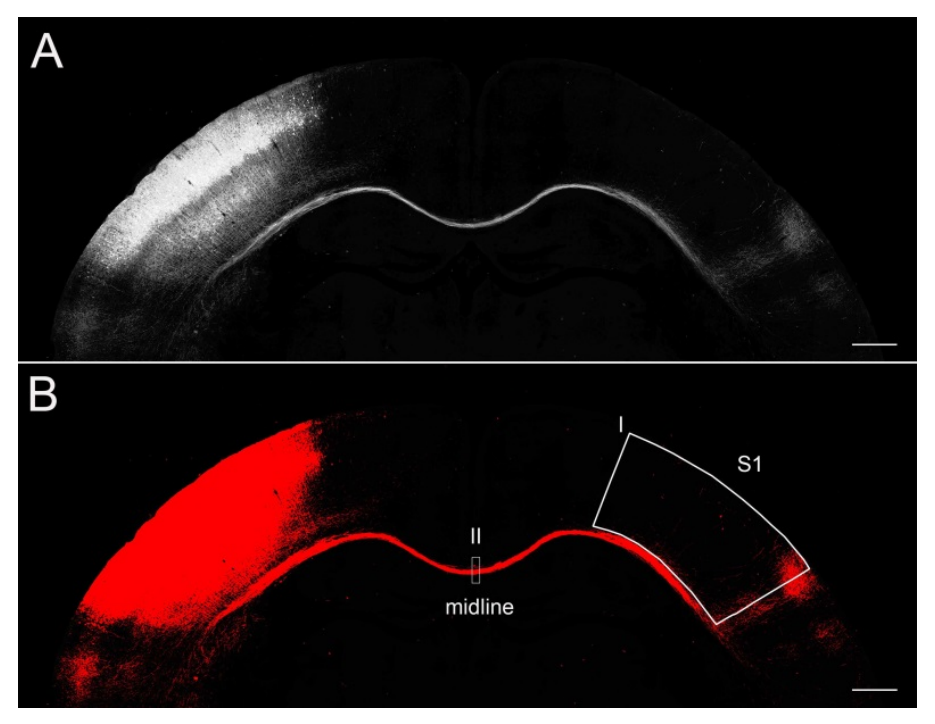

Figure 10: Callosal axon density analysis by Image J. (A) This picture was an 8-bit image. (B) Fluorescence signals within threshold in image A turned to red after setting up threshold range. Box I was drawn to encompass only the S1. Box II was used to measure axon density in the midline. 